\title{
Polyaniline-based biosensors
}

This article was published in the following Dove Press journal:

Nanobiosensors in Disease Diagnosis

27 July 2015

Number of times this article has been viewed

\section{Chetna Dhand' \\ Neeraj Dwivedi ${ }^{2}$ \\ Sachin Mishra ${ }^{3}$ \\ Pratima R Solanki ${ }^{4}$ \\ Venkatesh Mayandi' \\ Roger W Beuerman ${ }^{1,5}$ \\ Seeram Ramakrishna ${ }^{6}$ \\ Rajamani Lakshminarayanan ${ }^{1,5}$ \\ Bansi D Malhotra ${ }^{7}$ \\ 'Anti-Infectives Research Group, Singapore Eye Research Institute, Singapore; '2Department of Electrical and Computer Engineering, National University of Singapore, Singapore; ${ }^{3}$ School of Engineering, Gautam Buddha University, Greater Noida, India; ${ }^{4}$ Special Centre for Nanoscience, Jawaharlal Nehru University, New Delhi, India ${ }^{5}$ Duke-NUS SRP Neuroscience and Behavioral Disorders, Singapore; ${ }^{6}$ Center for Nanofibers and Nanotechnology, Department of Mechanical Engineering, National University of Singapore, Singapore; 'Department of Biotechnology, Delhi Technological University, Delhi, India}

Correspondence: Chetna Dhand; Rajamani Lakshminaryanan

Singapore Eye Research Institute, The Academia, 20 College Road, Discovery

Tower Level 6, Singapore 169856

Tel +65 $65767466 ;+6565767276$

Email chetna.dhand@seri.com.sg;

lakshminarayanan.rajamani@seri.com.sg

Bansi D Malhotra

Department of Biotechnology, Delhi

Technological University, Shahbad

Daulatpur, Main Bawana Road, Delhi

I I0042, India

Tel +9| 27294668

Email bansi.malhotra@gmail.com
Abstract: Biosensors are the subject of an immensely growing field of research owing to their broad range of applications in medicines, pharmacy, environmental monitoring, food and process control, defense and security, and principally in diagnostics. Diverse materials have been investigated for the advancement of biosensors in terms of their miniaturization, sophistication, cost, biosensing features, ie, detection limit, sensitivity, stability, selectivity, etc. Polyaniline (PANI) is one of the most interesting conductive polymers for biosensor design in view of its excellent electrochemical properties (polyelectrocatalytic characteristics, reversible redox behavior, and electrochemical tunability), straightforward processability, long-term environmental stability, and functionality-rich chemical structure. In this review, an attempt is made to compile almost all the existent literature on PANI-based biosensors in terms of enzymatic biosensors ( for $\mathrm{H}_{2} \mathrm{O}_{2}$, glucose, cholesterol, phenol/polyphenol/catecholamine detection), genosensors (DNA sensing), and immunosensors from 2006 to 2015. Furthermore, reports available on the biosensing of urea, uric acid, creatinine, pesticides, amino acids, and other clinically significant analytes are also assembled to provide a comprehensive overview on PANI-based biosensors.

Keywords: polyaniline, biosensor, direct electron transfer, mediator-free biosensor, conducting polymer, nucleic acid biosensor, immunosensor

\section{Introduction}

Biosensors are analytical devices integrated with biomolecules as the sensing element. They utilize the sensitivity and selectivity of biomolecules toward their corresponding analyte in conjunction with the physiochemical transducers to convert complex bioanalytical signals into simple easy-to-use signals. ${ }^{1}$ Biosensors are used chiefly in medical diagnostics, food safety, and environmental monitoring, and they also play a significant role in process management and bioterrorism control in the defense and security sector. ${ }^{2}$ The biosensors industry is now worth billions of US dollars, and the subject attracts the attention of national enterprises across the world, with more than tens of thousands of papers having been published in the area. The field of biosensors is broadly divided into two categories of instrumentation: 1) sophisticated, high-throughput laboratory machines capable of rapid, accurate, and convenient measurement of complex biological interactions and components; 2) easy-to-use, portable devices for use by nonspecialists for decentralizes, in situ, or home analysis. ${ }^{1}$ The basic concept of the biosensor was first illuminated by Clark and Lyons ${ }^{3}$ in his seminal description of an "enzyme electrode." With his invention of the Clark oxygen electrode, he introduced the concept of utilizing electrochemical detection of oxygen or hydrogen peroxide to design a broad range of bioanalytical devices to detect a range of bioanalytes/metabolites via 
their corresponding immobilized enzymes. Later, optical transducers based on bioaffinity immunosensors advanced the field of biosensors.

Enzymatic and bioaffinity-based biosensors both have applications in diagnostics. However, advancements in the field of nanomaterials and the growing concept of mediated electrochemistry with superior electrocatalysis have triggered the growth and development of simple, highly efficient, and precise enzymatic biosensors which are highly suitable for domestic use, and this industry has a turnover of US\$13 billion. ${ }^{1}$ Enzyme-assisted biosensors depend on oxidoreductase enzymes for being operational and commence the following biochemical reactions once in immediacy to their corresponding analyte:

$$
\begin{aligned}
& { }^{1} \mathrm{Sub}_{\text {red }}+\mathrm{Enz}_{\text {oxi }} \rightarrow{ }^{1} \mathrm{Sub}_{\text {oxi }}+\mathrm{Enz}_{\text {red }} \\
& { }^{2} \mathrm{Sub}_{\text {oxi }}+\mathrm{Enz}_{\text {red }} \rightarrow{ }^{2} \mathrm{Sub}_{\text {red }}+\mathrm{Enz}_{\text {oxi }}
\end{aligned}
$$

For instance, if we consider the working principle of cholesterol biosensor employing cholesterol oxidase enzyme (Enz), ${ }^{1} \mathrm{Sub}_{\text {red }},{ }^{1} \mathrm{Sub}_{\text {oxi }},{ }^{2} \mathrm{Sub}_{\text {oxi }}$, and ${ }^{2} \mathrm{Sub}_{\text {red }}$ in Equations 1 and 2 represent cholesterol, Cholestenone, $\mathrm{O}_{2}$, and $\mathrm{H}_{2} \mathrm{O}_{2}$, respectively. To limit the rate kinetics of Equation 2, a large excess of ${ }^{2} \mathrm{Sub}_{\text {oxi }}\left({ }^{2} \mathrm{Sub}_{\text {oxi }}\right)$ has to be provided. Thus, the overall rate of these biochemical reactions can be measured by monitoring either the rate of consumption of ${ }^{2} \mathrm{Sub}_{\text {oxi }}\left(\mathrm{O}_{2}\right)$ or the rate of formation of ${ }^{2} \mathrm{Sub}_{\text {red }}\left(\mathrm{H}_{2} \mathrm{O}_{2}\right)$. Monitoring the formation of $\mathrm{H}_{2} \mathrm{O}_{2}$ is comparatively simpler than measuring the depletion of $\mathrm{O}_{2}$. However, $\mathrm{H}_{2} \mathrm{O}_{2}$ estimation also has the disadvantage of receiving interference from a number of in vivo endogenous species (urea, ascorbate, acetaminophen) because of their similar oxidation potential. Moreover, it is not possible to monitor peroxide reduction as it is very difficult to search for a potential where peroxide can reduce but not $\mathrm{O}_{2}$. There are two ways of overcoming this problem: 1) introduce efficient artificial redox mediators (ferricyanide, ferrocene derivatives, organic dyes, etc) as a substitute for ${ }^{2} \mathrm{Sub}_{\text {oxi }}$. These mediators have the ability to shuttle the electron from the redox centers of the enzymes to the electrode surface at a much lower working potential. Thus, the analyte concentration can be measured indirectly by monitoring the mediator oxidation at a much lower electrochemical potential without much interference. These biosensors are called mediator-assisted biosensors. 2) The need for ${ }^{2} \mathrm{Sub}_{\text {oxi }}$ can be absolutely eradicated if the electrode material itself has the capability to receive the electron directly from the enzyme. This can be accomplished by wiring the electrode directly to the redox center of the enzymes utilizing certain conducting materials, thereby leading to the generation of mediator-free biosensors. Figure 1 shows the different electronic pathways for mediator-assisted and mediator-free biosensors.

To develop mediator-less biosensors, conducting polymers (CPs), including polyaniline (PANI), are efficient electrode material in view of their low redox potential and high conductivity, and thus act as a competent nondiffusional redox active system. ${ }^{4}$ Owing to its dual-redox couple,
A

Mediator-assisted biosensors

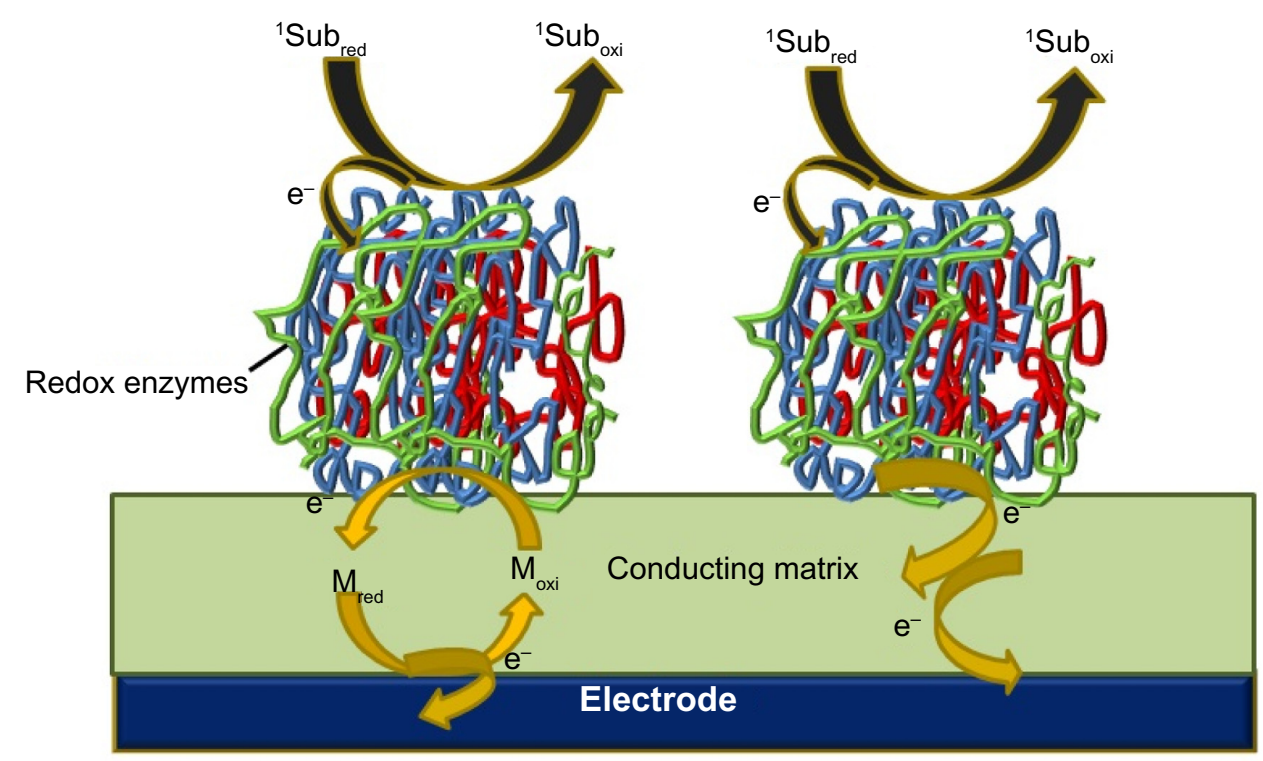

Figure I Schematic showing the electronic pathway for the electrochemical detection of the analyte via (A) mediator-assisted biosensors and (B) mediator-free biosensors. Abbreviation: e-, electron. 
excellent electrochemical characteristics, desirable chemical and mechanical stability, functionality-rich intrinsic structure and tunable features, PANI is one of the most explored polymers for the design of biosensors. ${ }^{5}$ In this review, an attempt has been made to survey the available literature on the investigations carried out into PANI's potential for biosensor development for different clinically important analytes including $\mathrm{H}_{2} \mathrm{O}_{2}$, glucose, cholesterol, DNA, catecholamine, polyphenol, urea, uric acid, creatinine, pesticides, etc. This review will provide a basic understanding about 1 ) the various features and properties of PANI that make it an appropriate candidate for biosensor design, 2) the implications of fabricating different PANI composites for biosensors, 3) the importance of PANI nanostructures for biosensor design, 4) the issues related to PANI-based biosensors, and 4) future prospects of PANI-based biosensors.

\section{Polyaniline and its structural significance for biosensor design}

Discovered in the 19th century, polyaniline, a semiflexible conducting polymer, has established itself as a versatile material in all foremost areas of science and technology including electrochromic devices, ${ }^{6}$ actuators, ${ }^{7}$ solar cells, ${ }^{8}$ tissue engineering, ${ }^{9}$ and biosensors. ${ }^{4}$ Its advantages include multiple color transitions, depending upon the environmental $\mathrm{pH}$ and its oxidation states; tunable conductivity and electrochemical behavior by monitoring the surrounding $\mathrm{pH}$, dopant type and doping intensity, oxidation state of PANI, morphology, thickness, and composite design; chemical, electrochemical, and environmental stability due to strong and stable heterocyclic aromatic backbone; easy processability due to the straightforward and variety of synthesis methods and its sufficient solubility in innumerable solvents; and capability to fabricate versatile composites/nanocomposites/nanobiocomposites in view of its functionality-rich chemical skeleton and low cost. These advantages make PANI a material with a broad spectrum of applications. All these features are related to its chemical structure. Chemically, PANI consists of " $n$ " reduced benzenoid diamine and " $m$ " oxidized quinoid diamine repeating units, where the oxidation state of PANI depends on the value of " $m$." Leucoemeraldine, emeraldine, and pernigraniline are the three different redox forms of PANI having $m: n$ ratio as $0: 1,1: 1$, and $1: 0$, respectively. ${ }^{4}$ Predominately imine groups but also the amine groups in PANI chains can be further protonated in the presence of $\mathrm{H}^{+}$(acidic) ion or the dopant to generate the cationic defects (polarons, bipolarons) that are responsible for the conductivity and redox behavior of PANI. The unprotonated and protonated forms of PANI are known as base and salt, respectively. ${ }^{10}$ Figure 2 shows different base and salt forms of PANI in its three redox forms. Conclusively, the conductivity of PANI can be tuned by using different doping agents, varying the extent of doping, and also by controlling the chain length and morphology including the dimensions and porosity of PANI. A discussion on the conductivity of PANI has been given in detail previously. ${ }^{4}$

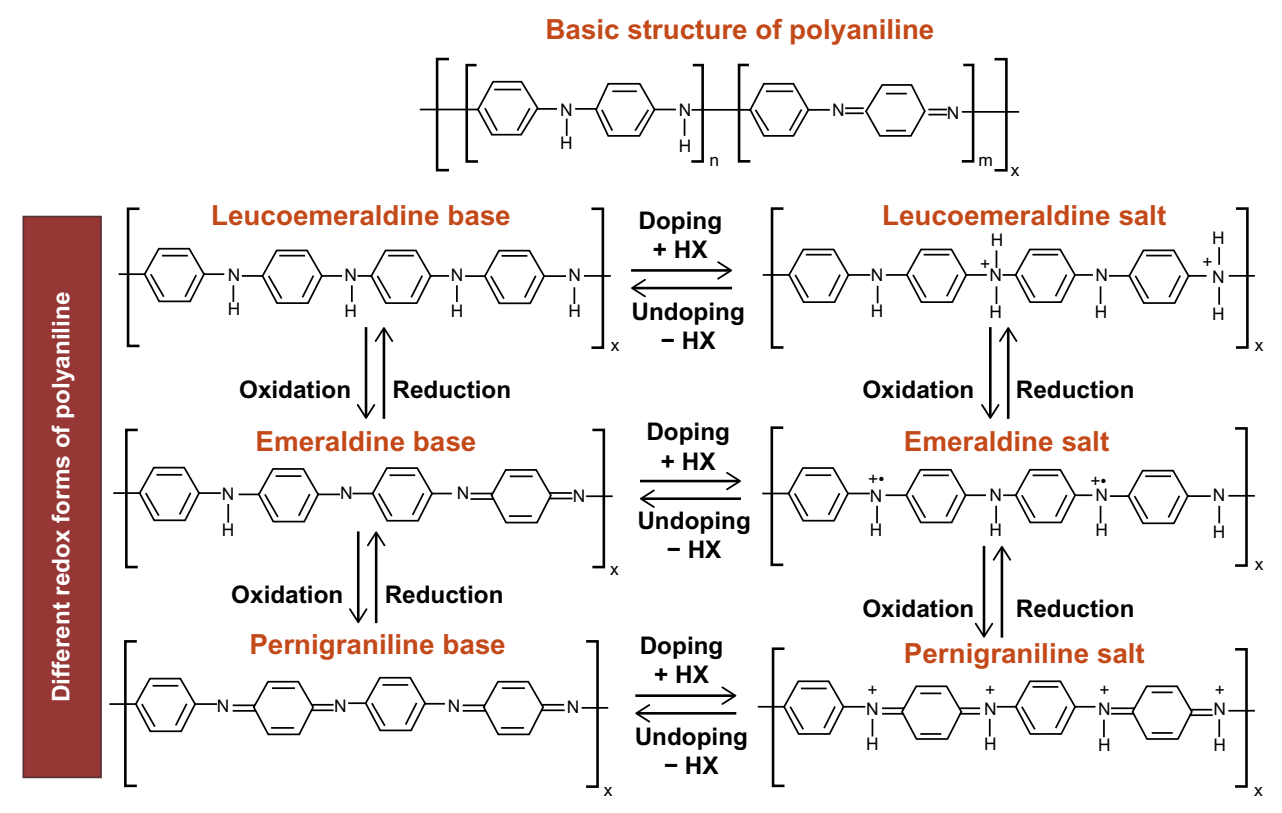

Figure 2 Basic structure of PANI and different redox forms of PANI with its doped states. Abbreviation: PANI, polyaniline. 
PANI is an efficient conducting platform for sensor and biosensor design because of its proficient redox behavior and its ability to mediate the electron shuttling between the reaction site to the electrode surface through biomolecules (in biosensors). The presence of two redox couples at appropriate electrochemical potential further helps PANI in facilitating the enzyme-polymer charge transfer processes, and makes it an ideal candidate to develop electrochemical biosensors. ${ }^{10}$ Consistent and sensitive interdependence between the electrochemical response and the $\mathrm{pH}$ of the electrolytic solution opens new avenues to develop another set of $\mathrm{pH}$ sensitive electrochemical biosensors specifically for the analytes that generate either acidic or basic moieties as end products of the biochemical reaction, eg, triglycerides. ${ }^{11}$ Thus, PANI acts as a self-reliant electron transfer mediator for the biosensors, obviating the need for any external diffusional mediators to accomplish the detection process (Figure 3A). Structurally, PANI is one of the best known CPs with adequate structural and chemical flexibility having a $\mathrm{NH}_{2}$-enriched chemical backbone that provides diverse prospects to bind/immobilize biomolecules, a key step for the construction of any type of biosensor. Employing these $\mathrm{NH}_{2}$ moieties and its positively charged chemical structure, biomolecules can be immobilized efficiently by covalent binding (using $N$-ethyl$N^{\prime}$-(3-dimethylaminopropyl) carbodiimide [EDC] and
$N$-hydroxysuccinimide [NHS], glutaraldehyde, etc), physical adsorption, and electrochemical entrapment (Figure 3B). Furthermore, precise control over the size/dimensions and shape of PANI by varying the synthesis strategies and processing parameters help to generate the desired physical and electrochemical properties for biosensor applications. Investigation of the efficient composite designs for PANI with a variety of conductive nanomaterials, eg, carbon nanotubes (CNT), graphene (GR), gold nanoparticles (AuNPs), platinum nanoparticles (PtNPs), etc, further expanded the utility of this material to develop highly sensitive, durable, and broad-ranging biosensors.

\section{Polyaniline-based biosensors Polyaniline-based peroxide biosensors}

Serving as an essential mediator, estimation of $\mathrm{H}_{2} \mathrm{O}_{2}$ detection is of considerable importance for environmental monitoring, food safety, and biomedical diagnostics. ${ }^{12}$ Thus, the development of sensitive and selective methods for $\mathrm{H}_{2} \mathrm{O}_{2}$ detection is highly desirable. The choice between the various existing spectroscopic and electrochemical methods always favors electrochemical methods for their fast response time and excellent sensitivity. In particular, electrochemical biosensors using peroxidase-modified electrodes (MEs) emerged as a promising choice by virtue of the intrinsic advantages

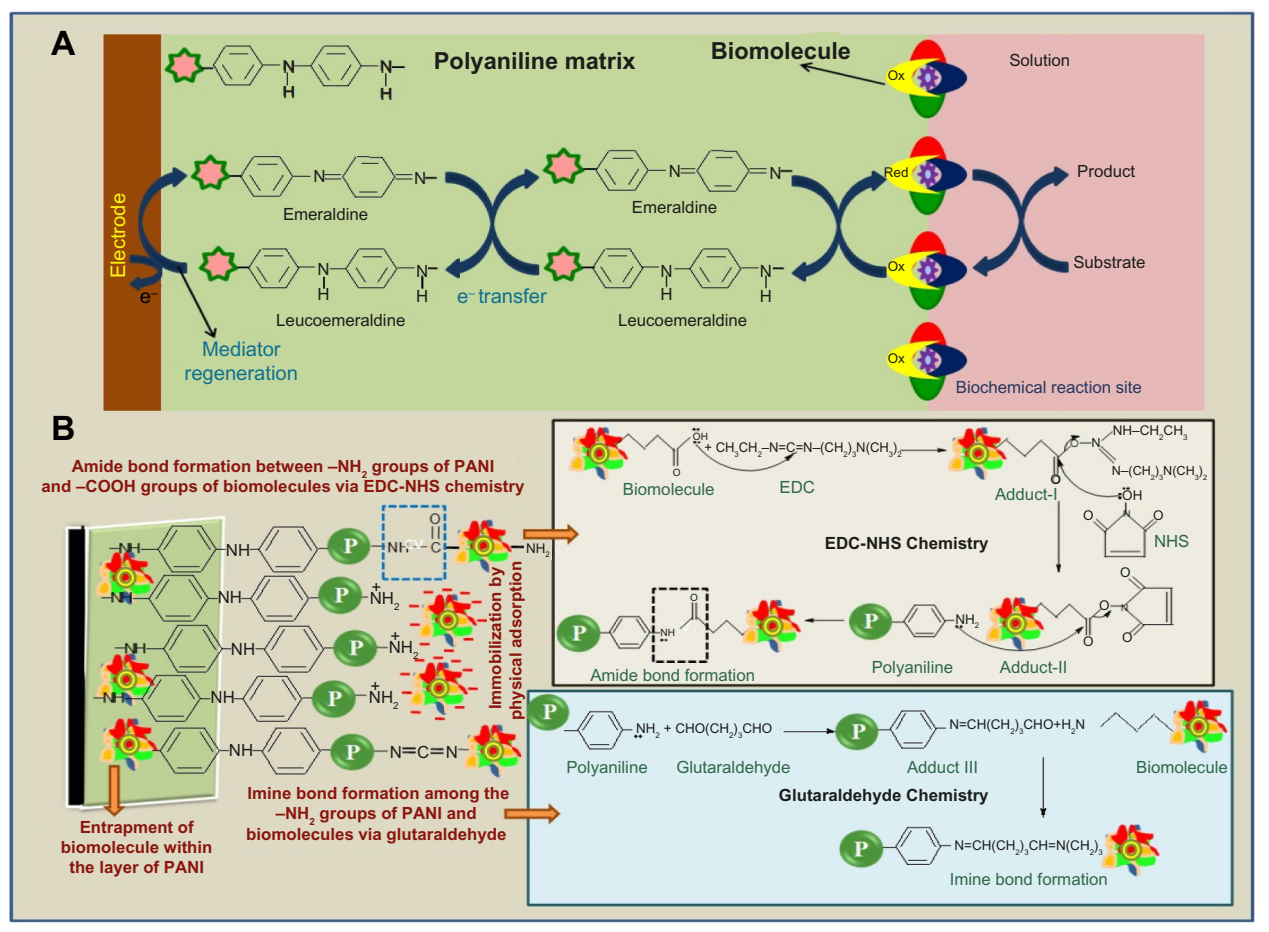

Figure 3 Schematic showing (A) polyaniline-mediated electron transfer process from the biochemical reaction site to the electrode surface for electrochemical biosensors. (B) Various immobilization strategies to bind biomolecules on the PANI matrix.

Abbreviations: PANI, polyaniline; EDC, N-Ethyl-N'-(3-methylaminopropyl) carbodiimide; NHS, N-hydroxysuccinimide; e-, electron. 
associated with their high catalytic activity and enzyme selectivity for their substrates. PANI, PANI nanostructures, and its composites were also studied for their role in the building up of peroxide biosensors. Solanki et al ${ }^{12}$ have demonstrated a sensitive amperometric and impedimetric biosensor developed by electrochemical entrapment of horseradish peroxidase (HRP) within the perchlorate $\left(\mathrm{ClO}_{4}^{-}\right)$ doped PANI network having a very short response time of merely $3 \mathrm{~s}$. Combining the advantages of high conductivity related to PANI and high surface area of the ordered mesoporous morphology, a mediator-free $\mathrm{H}_{2} \mathrm{O}_{2}$ biosensor has been constructed with improved sensor response and linearity. ${ }^{13}$ Chemically synthesized anthracene doped PANI nanofibers (PANI-NF, $300 \mathrm{~nm}$ ) were employed to immobilize HRP and then to investigate their biosensing response studies. ${ }^{14}$

To enhance the electrocatalytic behavior of PANI, metal nanoparticles were explored as the electron tunnelling centers and thus toward the development of highly sensitive thirdgeneration mediator-less biosensors. In this regard, Bao et $\mathrm{al}^{15}$ have utilized a green approach to fabricate polyaniline nanotubes (PANI-NT)/gold nanoparticles (AuNPs) hybrid nanostructures utilizing electrospun polyacrylonitrile (PAN) nanofibers as the sacrificial templates. Hollow nanotubular structures were shown to readily facilitate ion diffusion and improve the electronic response of the PANI nanotubes/ $\mathrm{Au}$ hybrid nanostructures to generate improved biosensing characteristics. ${ }^{15}$ To promote biocompatibility, electron transfer kinetics, and enzyme immobilization, PANI nanofibers (PANI-NF)-AuNPs composite with grooves was demonstrated for $\mathrm{H}_{2} \mathrm{O}_{2}$ biosensing with enhanced electrocatalytic features. ${ }^{16}$ Chen et $\mathrm{al}^{17}$ developed an amperometric $\mathrm{H}_{2} \mathrm{O}_{2}$ biosensor with a complex architecture of PtNPs incorporated inside electropolymerized PANI-NF films coated with a biofunctional hybrid film of AuNPs, chitosan (CS), and HRP. Long-term stability, good reproducibility, high sensitivity, and rapid detection are among the significant features displayed by these multicomponent bioelectrodes. In another interesting report, the synergistic electrochemical effect of $\mathrm{Au}-\mathrm{Pt} \mathrm{NPs} /$ nanoPANI/CS has been investigated to develop an improved amperometric $\mathrm{H}_{2} \mathrm{O}_{2}$ biosensor. ${ }^{18}$ Feng et $\mathrm{al}^{19}$ established a one-step synthesis of AgCl-PANI core-shell composite nanoparticles $(20-50 \mathrm{~nm})$ and showed their excellent redox behavior in neural solution that was then exploited to design faster amperometric biosensor for $\mathrm{H}_{2} \mathrm{O}_{2}$ detection. Song et $\mathrm{al}^{20}$ demonstrated the fabrication of a $\mathrm{H}_{2} \mathrm{O}_{2}$ sensor using chemiresistive silver nanoparticles (AgNPs)-modified PANI nanowires (PANI-NW). The authors reported high selectivity of these sensors toward $\mathrm{H}_{2} \mathrm{O}_{2}$ detection, which is related to the catalytic reaction of AgNPs with $\mathrm{H}_{2} \mathrm{O}_{2}$, leading to the generation of $\mathrm{OH}^{-}$ions, which further influence the conductivity of PANI.

Synergistic augmentation between PANI and CNT for facilitating the electron transfer rate has also been documented and utilized to construct improved $\mathrm{H}_{2} \mathrm{O}_{2}$ biosensor designs. In this context, Sheng et $\mathrm{al}^{21}$ revealed that the synergistic effect of GR-CNT hybrid materials, Au-Pt NPs, and the enzymatically induced deposition of PANI can provide an efficient platform for the design of novel electrochemical biosensors. Peroxide biosensors with enhanced stability and eight times more sensitivity were reported with HRP modified CNT doped PANI films. ${ }^{22} \mathrm{~A}$ three-dimensional porous network comprising of PANI chains, multiwalled carbon nanotubes (MWCNTs), and silica was demonstrated to achieve enhanced biosensing characteristics. Herein, PANI units with MWCNTs were reported to act as molecular cables to facilitate the electron transfer process from the redox center of the HRP to the electrode surface and thus lead to the production of third-generation biosensors. ${ }^{23}$ Table 1 illustrates the literature reports on HRP-modified PANI-based $\mathrm{H}_{2} \mathrm{O}_{2}$ biosensors.

\section{Polyaniline-based glucose biosensors}

Glucose biosensors have maintained their ever-growing significance in the biosensors market with major applications in home care diagnostics and in research laboratories. Amperometric biosensing platforms have gained much commercial attention compared with their fluorescent counterparts for glucose detection. The basic principle underlying amperometric glucose detection is clearly revealed in Equation 3, according to which glucose oxidase enzymes immobilized on bioelectrodes oxidize glucose molecules, resulting in the production of peroxide, which will be further detected electrochemically.

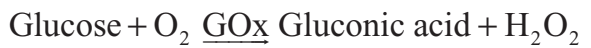

In the light of the World Health Organization's projection that the prevalence of diabetes will reach 552 million by 2030 , it is all the more necessary to ensure that regular blood glucose management continues for diabetic patients. With this in view, research is being directed toward upgrading and advancing the current biosensor designs to generate enhanced biosensing characteristics.

A glucose biosensor with enhanced bioelectrocatalyzed oxidation of glucose was described by Granot et $\mathrm{al}^{24}$ using single-walled carbon nanotubes (SWCNTs)/PANI hybrid system. The charge transport property is reported to be 


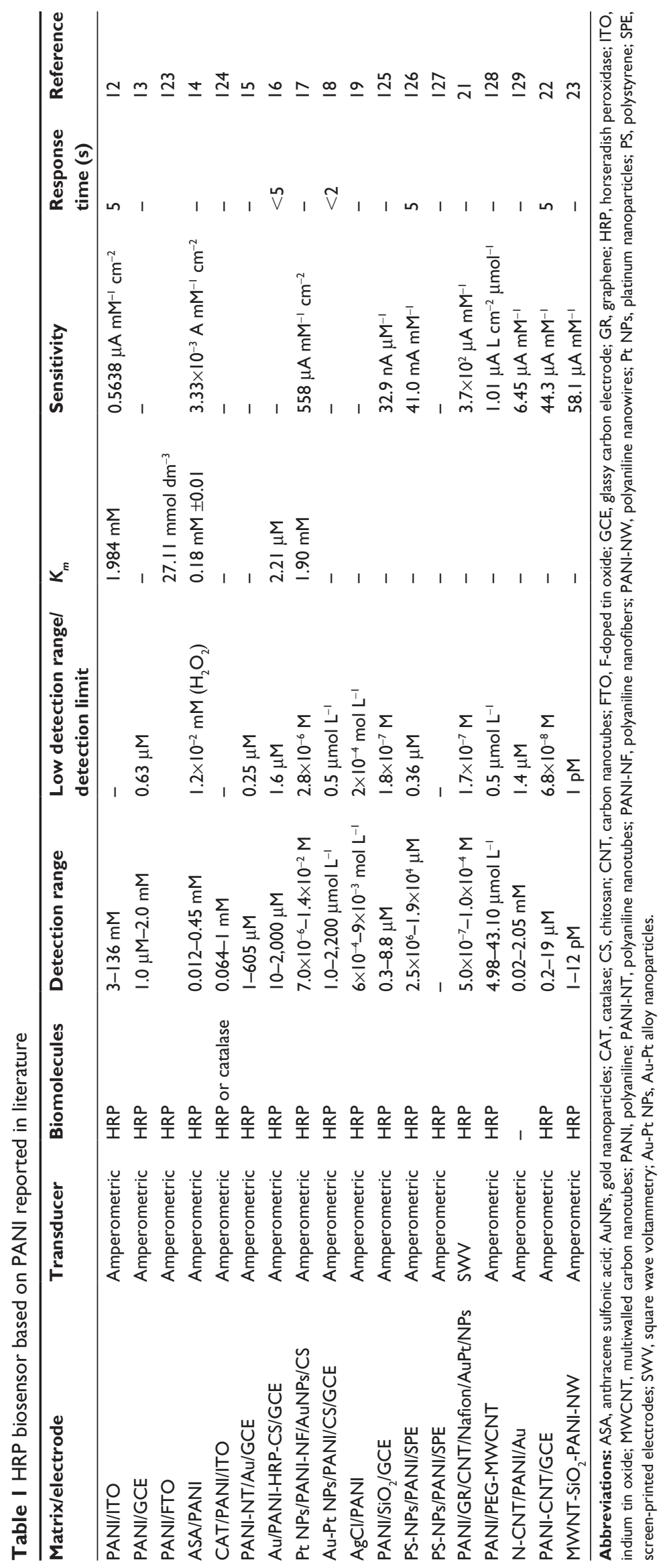


3.5 times higher when compared with the PANI/polystyrene sulfonate (PSS) system. A novel approach to the development of sensitive and stable glucose biosensors employing PANI-NF/AuNPs-based nanocomposite matrix was presented by Xian et al. ${ }^{25}$ PANI-grafted-CS/GOx multilayer film, investigated by $\mathrm{Xu}$ et al, ${ }^{26}$ for glucose detection provided a faster response with high output current. The porous morphology of PANI-GR composite film was analyzed by Zhou et $\mathrm{a}^{27}$ for glucose biosensing, and revealed remarkable biosensing features. In a comparative study among PANI, poly (o-anisidine) (POA) and their copolymer poly(aniline-co-o-anisidine) (PANI-co-POA), Borole et $\mathrm{al}^{28}$ verified that PANI-GOx shows the fastest response for glucose detection. Zou et $\mathrm{al}^{29}$ worked on PANI-Prussian Blue (PB)/MWCNTs, which presented a greatly enhanced $\mathrm{H}_{2} \mathrm{O}_{2}$ sensitivity of $508.18 \mu \mathrm{A}$ $\mathrm{mM}^{-1} \mathrm{~cm}^{-2}$ arising from synergy between the PANI-PB and MWCNTs.

$\mathrm{Xu}$ et $\mathrm{al}^{30}$ employed the interfacial polymerization method to synthesize PANI-NF and further immobilize GOx and cationic dendrimer-encapsulated Pt nanoparticles (Pt-DENs) on PANI/PSS surface by alternate layer-by-layer assembly. This method preserved the activity of enzyme molecules and also prevented the enzyme from leaking, thus providing a good operational stability of more than $20 \mathrm{~d}$. Core-shell nanocomposites comprised of PS, PANI, and AuNPs were prepared by Liu et $\mathrm{al}^{31}$ and indicated excellent redox ability in a wide range of $\mathrm{pH}$ values and higher electrical conductivity due to the presence of AuNPs, thus promoting direct electron transfer for mediator-free sensing. Liu et $\mathrm{al}^{32}$ have explored the advantage of PANI-CNT over PANI and derived PANIcoated $\mathrm{Fe}_{3} \mathrm{O}_{4} \mathrm{NPs}-\mathrm{CNT}$ composite by coprecipitation of $\mathrm{Fe}^{3+}$ and $\mathrm{Fe}^{2+}$ and in situ polymerization of aniline. A magnetic glucose biosensor was developed using the electrochemical doping of GOx in the composite, thus loading the composite magnetically on an electrode with the aid of a magnet, for glucose estimation. ${ }^{32}$ Since the magnetic composites could be removed by eliminating the magnet from electrode, this approach enhanced the functionality of renewable CNT-based biosensors. Shan et $\mathrm{al}^{33}$ have designed an electrochemical biosensor by in situ electropolymerization of aniline into a microporous poly (acrylonitrile-co-acrylic acid)-coated platinum electrode. The advantage of polymer porosity and electropolymerization is well implemented in this approach, which provided a highly sensitive and stable biosensor. Zhai et $\mathrm{al}^{34}$ designed a highly sensitive glucose biosensor using innovative composite heterostructures of GOx immobilized on PtNPs-PANI hydrogel. This PtNPs/PANI hydrogel heterostructure-based glucose sensor synergized the advantages of conducting hydrogel and catalytic nanoparticles and exhibited unprecedented sensitivity, as high as $96.1 \mu \mathrm{A} \mathrm{mM}^{-1} \mathrm{~cm}^{-2}$, with a response time of as fast as $3 \mathrm{~s}$, a linear range of $0.01-8 \mathrm{mM}$, and a low detection limit of $0.7 \mu \mathrm{M}$.

Zhao et $\mathrm{al}^{35}$ utilized PANI-NF as an electrode substrate for GOx immobilization, which showed good electrocatalytic oxidation features with a stability of over 2 wk. Similarly, Wang et $\mathrm{al}^{36}$ presented a glucose biosensor based on direct electron transfer reaction of GOx immobilized on PANI NT. With a good electrocatalytic activity toward oxidation of glucose, this biosensor also proved itself to be stable with good biological affinity and effective discriminant to interfering species such as ascorbic acid, uric acid, and 4-acetamidophenol, due to low detection potential. Efforts have been made by Xu et $\mathrm{al}^{37}$ to develop nanocomposites of MWCNTs-coated PANI and Pt-DENs. GOx is immobilized by cross-linking on Pt-DENs/ PANI/CNT composite for glucose detection for a wide linear range. Sheng and $Z_{\text {heng }}{ }^{38}$ presented a novel approach of covalently binding two enzymes, GOx and HRP, on PANI/ MWCNTs. PANI template by MWCNTs provided a headto-tail structure under the bienzyme biocatalytic condition. Wan et $\mathrm{al}^{39}$ investigated a composite design consisting of PANI, CS, and CNT for signal amplification to fabricate an efficient glucose biosensor. The resultant nanocomposite provided a biocompatible environment on electrode surface that increased the electrocatalytic activity and also enhanced the glucose affinity and sensitivity.

Kuczynska et $\mathrm{al}^{40}$ analyzed the effect of various surfactants on the biosensing properties of PANI. The analysis revealed better immobilization of GOx onto PANI-Tween 20 and PANITween 40 matrix with enhanced biosensing response. It also proved that the use of surfactant can enhance the response time of PANI-based biosensors. A highly sensitive glucose biosensor (detection limit of $4 \mathrm{pM}$ ) was developed by Yan et $\mathrm{al}^{41}$ using AuNPs-AgCl@PANI hybrid material. Ozdemir et $\mathrm{al}^{42}$ demonstrated a novel pyranose oxidase (PyOx)-based biosensor with AuNPs-PANI/AgCl/gelatin modified glassy carbon (GC) electrode. The nanocomposite and PyOx integration helped in higher stability and bioactivity of enzyme for biosensing. Song et $\mathrm{al}^{43}$ fabricated boron-doped diamond electrodes covered by PANI-PtNPs composite, and observed a very low detection limit of $0.10 \mu \mathrm{M}$. Wu and $\mathrm{Yin}^{44}$ presented a novel glucose biosensor based on boron nitride nanotubes (BNNTs)-PANI-PtNPs hybrid with a response time of $3 \mathrm{~s}$. Tamer et $\mathrm{al}^{45}$ established that PANI-gold nanorod is efficient for enzyme immobilization and also preserves the native structure of GOx. The advantage of this approach over others is ease of preparation and a rapid response time of less than $3 \mathrm{~s}$. 
Nguyen et $\mathrm{al}^{46}$ described a $\mathrm{GR} / \mathrm{Fe}_{3} \mathrm{O}_{4} / \mathrm{PANI} / \mathrm{GOx}$ system having GR patterned interface with an improved sensitivity of $47 \mu \mathrm{A} \mathrm{mM}{ }^{-1} \mathrm{~cm}^{-2}$. Chen et $\mathrm{al}^{47}$ explored a macro-porous self-doped PANI/PB hybrid fabricated by step-by-step electrodeposition. The large surface area and excellent conductivity of these electrodes provided a wide range of linear detection $(2-1,600 \mu \mathrm{M})$ and a low detection limit of $0.4 \mu \mathrm{M}$. An excellent sensitivity of $99.4 \mu \mathrm{A} \mathrm{mM} \mathrm{mm}^{-1} \mathrm{~cm}^{-2}$ was obtained with high biological affinity toward glucose. Qiu et $\mathrm{al}^{48}$ used PANI-modified graphene nanosheets with $\mathrm{Pt}$ as a hybrid system, in which a sensitivity of $131.7 \mu \mathrm{A} \mathrm{mM} \mathrm{mM}^{-1} \mathrm{~cm}^{-2}$ was obtained with a detection limit of $0.18 \mu \mathrm{m}$.

Xiang et $\mathrm{al}^{49}$ demonstrated the application of cytochrome c (Cyt c)/AuNPs/polyaniline nanospheres (PANI-NS) MEs for glucose detection, and thus provided a novel nanocompositebased electrochemical platform with a detection limit of 0.01 $\mathrm{mM}$ and less than $5 \mathrm{~s}$ response time. Zhai et $\mathrm{al}^{50}$ explored PtNPs/PANI hydrogel heterostructures that had the advantage of both conducting hydrogel and nanoparticle catalyst. The porous structure of hydrogel provided high-density immobilization of enzyme, which further helped to efficiently catalyze the oxidation of glucose. Thakur et $\mathrm{al}^{51}$ explored pectin-coated PANI nanoparticles (PANI-NPs) in which biopolymer pectin acts as a stabilizer for the colloidal nanoparticles. The high surface area and rapid electron transfer resulted in sensitivity that was three times as high as that $\left(79.49 \mu \mathrm{A} \mathrm{mM}^{-1} \mathrm{~cm}^{-2}\right)$ of PANI. A tunable direct bioelectrocatalysis was presented by Sarauli et $\mathrm{al}^{52}$ using sulfonated PANI copolymers as matrices for the entrapment of pyrroloquinoline quinone-dependent glucose dehydrogenase (PQQ-GDH), by fabricating a multilayered enzyme network via layered polymer deposition. Antiochia et $\mathrm{al}^{53}$ utilized osmium redox complex as electrochemical mediator with PANI for glucose sensing. The mediator was coimmobilized during the polymerizing procedure. A linear range of detection from 5 to $65 \mathrm{mM}$ was obtained with a stability of more than $40 \mathrm{~d}$. Similarly, $\mathrm{Xu}$ et $\mathrm{al}^{54}$ demonstrated the enzyme retention activity and good electrical conductivity of GR/PANI/AuNPs in biosensors. With a fabulous catalytic activity, the electrode showed a detection limit of $0.6 \mu \mathrm{M}$. Zhang et $\mathrm{al}^{55}$ explored the application of PANI microtubes with GOx as a model redox protein. When compared with GOx/ PANI film (1 mM) and GOx/PANI NW (50 mM), the detection limit obtained was much better with a quick response of $3 \mathrm{~s}$. Pahurkar et $\mathrm{al}^{56}$ presented a novel approach of evanescent wave absorption based, cladding modified, fiber optic intrinsic glucose biosensor. In this, GOx was immobilized by crosslinking through glutaraldehyde on PANI supportive matrix, deposited on a core of optical fiber. A very low detection limit of $10 \mathrm{nM}$ was obtained with its stability for $36 \mathrm{~d}$. Tang et $\mathrm{al}^{57}$ demonstrated the application of nanometer-sized $\mathrm{TiO}_{2}$ $\left(\mathrm{n}-\mathrm{TiO}_{2}\right.$ ) and glassy carbon electrode (GCE) to prepare $\mathrm{GOx} / \mathrm{n}$ $\mathrm{TiO}_{2} / \mathrm{PANI} / \mathrm{GCE}$-based electrode. The sensor showed a good response with a detection limit of $18 \mu \mathrm{M}$ and a shelf life of up to $30 \mathrm{~d}$. Table 2 shows the biosensing parameters for different PANI matrices for glucose detection.

\section{Polyaniline-based cholesterol biosensors}

Cholesterol in plasma lipoprotein which can be found in the free form, esterified to long-chain fatty acids (cholesteryl esters), and in other covalent and noncovalent linkages in animal tissues. The normal amount of cholesterol in the human body is $130-260 \mathrm{mg} / 100 \mathrm{~mL}$ of the blood plasma. Once this limit exceeds, cholesterol starts depositing/sticking on the walls of the arteries as plaque, making them thicker, harder, inflexible, and leading to the slowing down or, occasionally, complete blockage of the blood flow to the heart. This results in many clinical disorders including hypertension, arteriosclerosis, myocardial infarction, neurological complications, etc. Thus, cholesterol estimation is a very important parameter for clinical diagnosis. Various calorimetric and spectrophotometric protocols are available for cholesterol estimation; however, poor specificity, instability of the related reagents, and selectivity of these methods demand the development of more efficient enzyme-based biosensors for its quantification. Efforts are continuously on to develop enzymatic biosensors for cholesterol detection, and polyaniline is among the leading materials investigated in this course. Figure 4 shows different enzymatic strategies adopted by different researchers to design optical and electrochemical biosensors for free cholesterol and total cholesterol detection with PANI as the immobilization platform.

At the onset of exploring PANI for cholesterol biosensors, the focus was more on the electrochemically polymerized PANI films. ${ }^{58,59}$ Singh et al ${ }^{58}$ have attempted to modify the electrochemically deposited PANI films using cholesterol oxidase (CHOx), cholesterol esterase (ChEt), and HRP enzymes and investigated their optical and electrochemical biosensing response, toward total cholesterol, following the pathways 4 and 5 shown in Figure 4. The designed bioelectrodes showed wide detection range, decent sensitivity, and reasonable stability; however, there is enough scope for improvement in the response time and the apparent Michaelis-Menten constant $\left(K_{m}^{\mathrm{app}}\right)$ parameter (indicative of enzyme-analyte interactions) of these bioelectrodes. Dhand et $\mathrm{al}^{60}$ have proposed, for the first time, the applicability of electrophoretically deposited nanostructured PANI films headed for cholesterol biosensor 


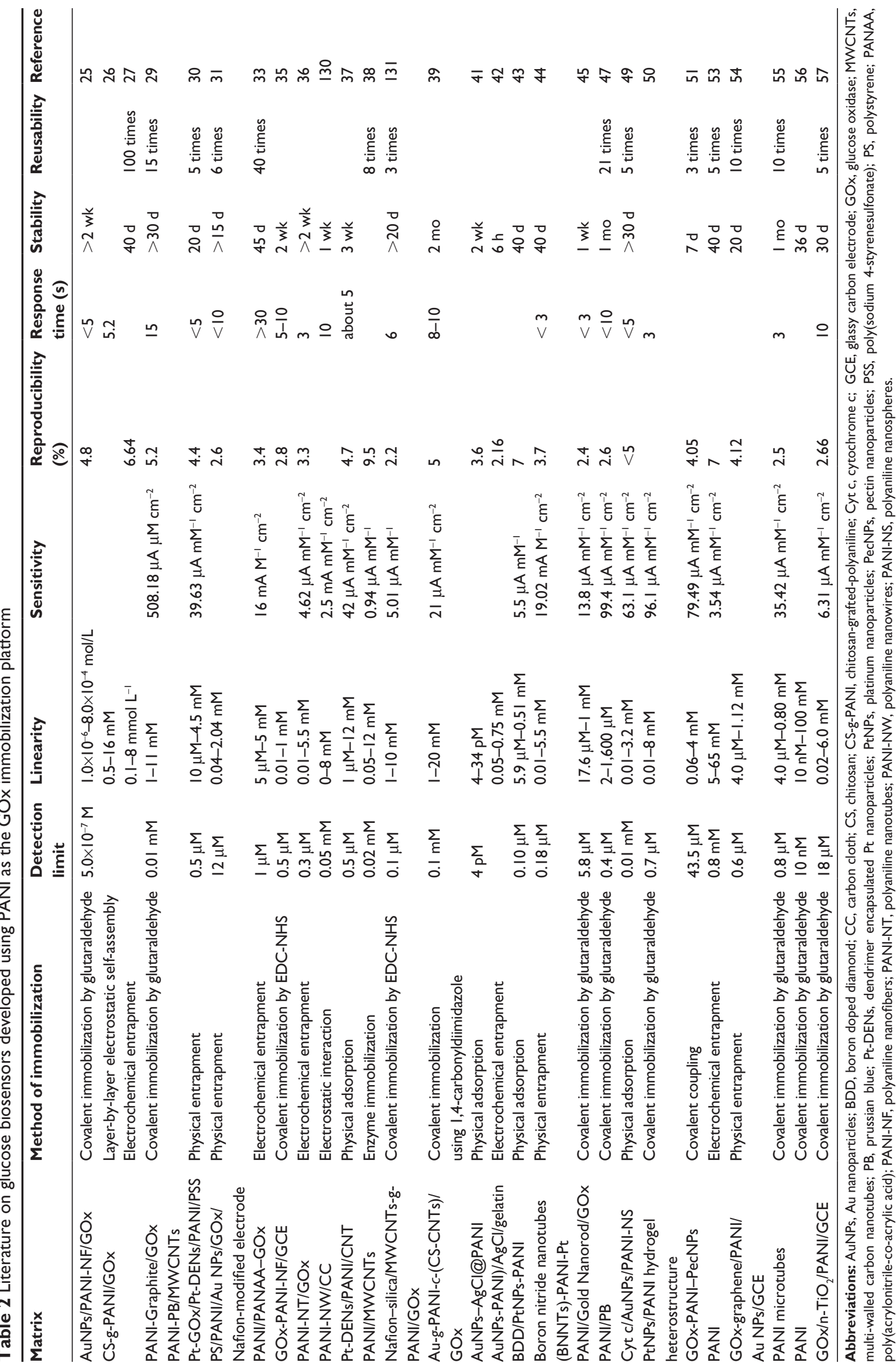




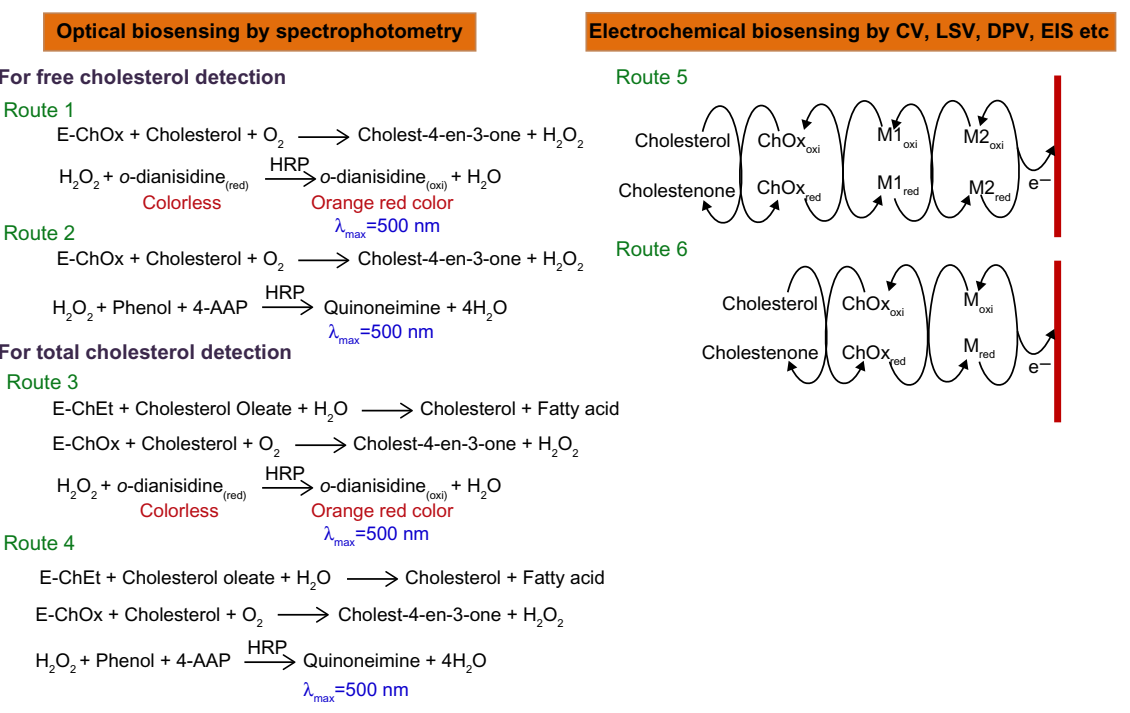

Figure 4 Various biochemical pathways adopted for designing optical and electrochemical biosensors for cholesterol detection using PANI as the enzyme immobilization platform.

Abbreviations: 4-AAP, 4-aminoantipyrine; CHOx, cholesterol oxidase; ChEt, cholesterol esterase; CV, cyclic voltammetry; DPV, differential pulse voltammetry; E, enzyme; $\mathrm{e}^{-}$, electron; EIS, electrochemical impedance spectroscopy; HRP, horseradish peroxidases; LSV, linear sweep voltammetry; M, mediator; PANI, polyaniline.

development. The authors adopted the $o$-dianisidine strategy (route 1 in Figure 4) for estimating the photometric response of the fabricated bioelectrodes, and showed enhanced cholesterol oxidase-cholesterol interactions, revealed by a low $K_{m}^{\text {app }}$ value, on these electrophoretically fabricated PANI matrices. Convinced with the performance of electrophoretically fabricated matrices, the authors have also studied the application of electrophoretically deposited PANI nanotubes film for cholesterol detection. ${ }^{61}$ Response studies carried out using linear sweep voltammetry and photometric studies demonstrate large effectiveness of ChOx-PANI-NT/ITO electrodes in the wide-ranging detection of cholesterol (25-500 $\left.\mathrm{mg} \mathrm{dL}^{-1}\right)$ with enhanced sensitivity $\left(3.36 \mathrm{~mA} \mathrm{mg}^{-1} \mathrm{dL}\right)$ and very short response time (30 s). In another attractive report, PANI nanospheres (PANI-NS) were synthesized using the ethylene glycolmediated morphological transformation strategy and were explored for cholesterol biosensing. ${ }^{62}$ The ChOx-PANI-NS/ ITO bioelectrodes were found to be highly efficient in detecting cholesterol in the physiological range with superior sensitivity, fast response time, and enhanced shelf life. Matharu et $\mathrm{l}^{63}$ have studied PANI-stearic acid (SA) Langmuir-Blodgett (LB) films for cholesterol biosensor development. The authors observed a high affinity of the ChOx/Glu/PANI-SA LB film/ITO bioelectrodes for cholesterol because of the ordered arrangement of the PANI molecules that facilitates uniform distribution of ChOx in desirable conformation.

Work has also been carried out to explore modified PANI matrices and their composites to demonstrate their influence on cholesterol detection efficiency. In this regard, Dhand et a ${ }^{64}$ have reported the fabrication of PANI-CNT composites by the electrophoretic route and then investigated the role of this electrocatalytically improved matrix in cholesterol biosensor design. Biosensing studies have found enhanced sensitivity, smaller response time (10 s), and high electrode stability (12 wk) related to ChOx/PANI-CNT/ITO electrodes. ${ }^{65}$ In another related report, Nguyen et al ${ }^{66}$ developed mediatorsupported cholesterol biosensor using ChOx immobilized on electropolymerized PANI-MWCNT matrix with potassium ferricyanide $\left(\mathrm{K}_{3}\left[\mathrm{Fe}(\mathrm{CN})_{6}\right]^{3-}\right)$ as the mediator. Manesh et al ${ }^{67}$ have designed a silica-PANI bienzyme cholesterol biosensor system by electrochemical entrapment of ChOx and HRP during poly( $N[3$-(trimethoxysilyl)propyl]aniline) (PTMSPA) polymerization. This biosensor was found to operate at very low electrochemical potential $(-150 \mathrm{mV})$ since the modified PANI matrix facilitates the direct electron transfer between the electrode and the redox center of HRP. This PTMSPAHRP/ChOx-ME demonstrates excellent analytical performance with a detection limit of 1-25 mM, high sensitivity, and selectivity. In another interesting investigation, Ruecha et $\mathrm{al}^{68}$ have fabricated nanocomposite composed of GR, polyvinylpyrrolidone (PVP), and PANI by a high-potential assisted electrospraying technique for preparing paper-based cholesterol biosensors. The electrode enriched with GR/PVP/ PANI nanostructures $(160 \pm 1.02 \mathrm{~nm})$ was used for ChOx immobilization, and its biosensing response was estimated. The results revealed enhanced electrocatalytic activity of the bioelectrodes toward $\mathrm{H}_{2} \mathrm{O}_{2}$ oxidation, owing to enhanced conductivity of the electrodes by ingrained GR, which leads to the improved sensitivity of the biosensor. Zhang et al ${ }^{69}$ attempted to formulate third-generation biosensors for 
cholesterol sensing, employing the phenomenon of direct electron shuttling between the ChOx enzyme and the electrode surface composed of PANI/Au nanocomposites. The designed biosensors reveal rapid (RT: $3 \mathrm{~s}$ ) and interferencefree amperometric response to cholesterol. In another work, the authors have attempted to investigate CS-based PANI-Au nanocomposites for the determination of cholesterol. ${ }^{70} \mathrm{With}$ wide-range linearity, high sensitivity, and better shelf life, these bioelectrodes facilitate enzyme-substrate interaction indicated by a very low $K_{m}^{a p p}$ value $\left(10.84 \mathrm{mg} \mathrm{dL}^{-1}\right)$. Shin et $\mathrm{al}^{71}$ have investigated electrospun PANI/polystyrene (PS) blended fibers, with layer-by-layer electrostatic adsorption of ChOx, for amperometric cholesterol biosensor design. Table 3 shows the different PANI matrices employed for cholesterol biosensor development by different research groups with their biosensing characteristics.

\section{Polyaniline-based nucleic acid biosensors}

DNA biosensors have attracted immense scientific interest owing to their key potential in disease diagnosis, gene analysis, biological warfare detection, and forensic applications. This field has been enriched further with the discovery of new genetic loci specific to hereditary genetic diseases, following the completion of the Human Genome Project. Owing to their great scope, enormous efforts have been made to develop cost-effective and rapid DNA biosensors with improved selectivity and sensitivity. Gene chips, DNA microarrays, and lab-on-a-chip are structurally

Table 3 Biosensing characteristics of the cholesterol biosensors developed using polyaniline as the transducer material

\begin{tabular}{|c|c|c|c|c|c|c|c|}
\hline Matrix used & Sensing element & $\begin{array}{l}\text { Transducer } \\
\text { employed }\end{array}$ & Linearity & $\begin{array}{l}\text { Sensitivity and } \\
\text { response time }\end{array}$ & $\begin{array}{l}\text { Shelf life and } \\
\text { reusability }\end{array}$ & $K_{m}^{a p p}$ value & Reference \\
\hline $\begin{array}{l}\text { Electrochemically } \\
\text { prepared PANI film }\end{array}$ & $\begin{array}{l}\text { ChOx, ChEt, HRP } \\
\text { MOI: covalent } \\
\text { cross-linking using } \\
\text { glutaraldehyde }\end{array}$ & Optical & $50-500 \mathrm{mg} \mathrm{dL}{ }^{-1}$ & $\mathrm{RT}: 240 \mathrm{~s}$ & $6 \mathrm{wk}$ & $75 \mathrm{mg} \mathrm{dL}^{-1}$ & 58 \\
\hline $\begin{array}{l}\text { Electrochemically } \\
\text { prepared PANI } \\
\text { film }\end{array}$ & $\begin{array}{l}\text { ChOx, ChEt, MOI: } \\
\text { MOI: } \\
\text { covalent cross-linking } \\
\text { using glutaraldehyde }\end{array}$ & Electrochemical & $100-500 \mathrm{mg} \mathrm{dL}^{-1}$ & $\begin{array}{l}7.5 \times 10^{-4} \mathrm{nA} \mathrm{mg}^{-1} \mathrm{dL} \\
\text { RT: } 40 \mathrm{~s}\end{array}$ & $6 \mathrm{wk}$ & - & 59 \\
\hline $\begin{array}{l}\text { Electrophoretically } \\
\text { deposited } \\
\text { nanostructured } \\
\text { PANI film }\end{array}$ & $\begin{array}{l}\text { ChOx MOI: covalent } \\
\text { cross-linking using } \\
\text { EDC-NHS }\end{array}$ & Optical & $25-400 \mathrm{mg} \mathrm{dL}-1$ & $7.76 \times 10^{-5} \mathrm{Abs} \mathrm{mg}^{-1} \mathrm{dL}$ & $\begin{array}{l}\text { I I wk, } \\
20 \text { times }\end{array}$ & $26.14 \mathrm{mg} \mathrm{dL}^{-1}$ & 60 \\
\hline $\begin{array}{l}\text { Electrosprayed } \\
\text { nanocomposite of } \\
\text { PANI, GR, and PVP }\end{array}$ & $\begin{array}{l}\text { ChOx MOI: Physical } \\
\text { Adsorption }\end{array}$ & Electrochemical & $50 \mu \mathrm{M}-10 \mathrm{mM}$ & $34.77 \mu \mathrm{A} \mathrm{mM} \mathrm{m}^{-1} \mathrm{~cm}^{-2}$ & $\begin{array}{l}2 \text { wk, } \\
5 \text { times }\end{array}$ & - & 68 \\
\hline $\begin{array}{l}\text { PANI Langmuir- } \\
\text { Blodgett film }\end{array}$ & $\begin{array}{l}\text { ChOx MOI: covalent } \\
\text { cross-linking using } \\
\text { glutaraldehyde }\end{array}$ & $\begin{array}{l}\text { Electrochemical } \\
\text { and optical }\end{array}$ & $25-400 \mathrm{mg} \mathrm{dL}{ }^{-1}$ & $88.9 \mathrm{nA} \mathrm{mg}^{-1} \mathrm{dL}$ & $10 \mathrm{wk}$ & $46.83 \mathrm{mg} \mathrm{dL}^{-1}$ & 63 \\
\hline $\begin{array}{l}\text { Electrophoretically } \\
\text { deposited } \\
\text { PANI-CNT } \\
\text { composite }\end{array}$ & $\begin{array}{l}\text { ChOx MOI: covalent } \\
\text { cross-linking } \\
\text { using EDC-NHS } \\
\text { chemistry }\end{array}$ & $\begin{array}{l}\text { Amperometric/ } \\
\text { optical }\end{array}$ & $50-500 \mathrm{mg} \mathrm{dL}{ }^{-1}$ & $\begin{array}{l}6,800 \mathrm{nA} \mathrm{mM}^{-1} \mathrm{RT}: \\
10 \mathrm{~s}\end{array}$ & $12 w k$ & - & 65 \\
\hline $\begin{array}{l}\text { Electrochemically } \\
\text { deposited poly } \\
\text { (aniline-co-pyrrole) }\end{array}$ & $\begin{array}{l}\text { ChOx MOI: covalent } \\
\text { cross-linking using } \\
\text { EDC-NHS }\end{array}$ & $\begin{array}{l}\text { Amperometric/ } \\
\text { optical }\end{array}$ & $1-10 \mathrm{mM}$ & $\begin{array}{l}93.35 \mu \mathrm{A} \mathrm{mM}{ }^{-1} \mathrm{RT}: \\
30 \mathrm{~s}\end{array}$ & $7 \mathrm{wk}$ & - & 132 \\
\hline $\begin{array}{l}\text { Chitosan-based } \\
\text { PANI-Au } \\
\text { nanocomposite }\end{array}$ & $\begin{array}{l}\text { ChOx MOI: Physical } \\
\text { Adsorption }\end{array}$ & Amperometric & $50-500 \mathrm{mg} \mathrm{dL^{-1 }}$ & $\begin{array}{l}0.86 \mu \mathrm{A} \mathrm{mg}^{-1} \mathrm{dL} \mathrm{RT}: \\
20 \mathrm{~s}\end{array}$ & $\begin{array}{l}3 \text { wk, } \\
20 \text { times }\end{array}$ & $10.84 \mathrm{mg} \mathrm{dL}^{-1}$ & 70 \\
\hline $\begin{array}{l}\text { Electrochemically } \\
\text { deposited PANI } \\
\text { film }\end{array}$ & $\begin{array}{l}\text { ChOx MOI: covalent } \\
\text { cross-linking using } \\
\text { glutaraldehyde }\end{array}$ & $\begin{array}{l}\text { Amperometric/ } \\
\text { optical }\end{array}$ & $5-400 \mathrm{mg} \mathrm{dL}^{-1}$ & $13 \mid \mu \mathrm{A} \mathrm{mg} g^{-1} \mathrm{dL}$ & $\begin{array}{l}10 \text { wk, } \\
20 \text { times }\end{array}$ & $2.2 \mathrm{mg} \mathrm{dL}^{-1}$ & 133 \\
\hline $\begin{array}{l}\text { Electrochemically } \\
\text { deposited Si-PANI } \\
\text { composite }\end{array}$ & $\begin{array}{l}\text { ChOx/HRP MOI: } \\
\text { electrochemical } \\
\text { entrapment }\end{array}$ & Amperometric & $\mathrm{I}-25 \mathrm{mM}$ & $\begin{array}{l}0.123 \mathrm{~mA} \mathrm{M} \mathrm{M}^{-1} \\
\text { RT: } 6 \mathrm{~s}\end{array}$ & $\begin{array}{l}4 \text { wk, } \\
9 \text { times }\end{array}$ & - & 67 \\
\hline $\begin{array}{l}\text { Polyaniline } \\
\text { nanospheres }\end{array}$ & $\begin{array}{l}\text { ChOx MOI: covalent } \\
\text { cross-linking using } \\
\text { EDC-NHS }\end{array}$ & Amperometric & $25-500 \mathrm{mg} \mathrm{dL}-1$ & $\begin{array}{l}\text { I. } 3 \times 10^{-3} \mathrm{~mA} \mathrm{mg}^{-1} \mathrm{dL} \\
\text { RT: } 10 \mathrm{~s}\end{array}$ & $\begin{array}{l}12 \text { wk, } \\
10 \text { times }\end{array}$ & $2.5 \mathrm{mM}$ & 62 \\
\hline
\end{tabular}

Abbreviations: CNT, carbon nanotubes; ChEt, cholesterol esterase; ChOx, cholesterol oxidase; EDC, N-Ethyl-N'-(3-methylaminopropyl) carbodiimide; GR, graphene; HRP, horseradish peroxidase; MOI, method of immobilization; NHS, N-hydroxysuccinimide; PANI, polyaniline; PVP, polyvinylpyrrolidone. 
advanced, miniaturized, and multicomponent versions of DNA biosensor design. DNA biosensors need a transducer surface for the immobilization of the single standard (ss) probe DNA. Depending upon the transducer employed, duplex formation or hybridization in the presence of the complementary DNA will be detected in the form of variation in the optical signal, electrochemical response, or in terms of mass change.

PANI is one of the massively explored matrices for designing DNA biosensors. Arora et al ${ }^{72}$ constructed an Escherichia coli genosensor by immobilizing 5'-biotin-labeled E. coli probe (BdE) on electrochemically deposited avidin-modified PANI films. The designed genoelectrode was investigated for its sensing response using methylene blue (MB) as hybridization indicator, and was found to electrochemically detect a complementary target probe $\left(0.009 \mathrm{ng} \mu \mathrm{L}^{-1}\right)$, E. coli genomic DNA $\left(0.01 \mathrm{ng} \mu \mathrm{L}^{-1}\right)$ and 11 E. coli cells $\mathrm{mL}^{-1}$ in $60 \mathrm{~s}$ to 14 min hybridization time without employing PCR. In another report, the authors performed the hybridization detection of $E$. coli DNA with the guanine oxidation strategy and compared it with the detection parameters using MB as a redox electrocatalytic indicator. The results showed enhancement of the detection limit to nearly 100 times with MB in comparison with the guanine oxidation protocol. ${ }^{73}$ By the same token, Prabhakar et $\mathrm{al}^{74}$ developed a nucleic acid biosensor for Mycobacterium tuberculosis (M. tuberculosis) utilizing $\mathrm{NH}_{2}$-modified DNA and peptide nucleic acid (PNA) probe, specific to the pathogen, with PANI as the immobilization platform. PNA-PANI/Au electrodes exhibit improved specificity $(1,000$ times $)$ and detection limit $\left(0.125 \times 10^{-18} \mathrm{M}\right)$ compared with DNA-PANI/Au electrode $\left(2.5 \times 10^{-18} \mathrm{M}\right)$. The authors have also reported superior electrochemical nucleic acid biosensor for organophosphorus pesticide detection using PANI-polyvinyl sulfate (PVS) matrix having double standard calf thymus DNA as the sensing element. ${ }^{75} \mathrm{Hu}$ et al ${ }^{16}$ utilized a self-doped PANI-DNA hybrid as the platform to build highly sensitive electrochemical DNA biosensor with label-free, reagentless, and self-signal amplifying features. An ultrasensitive assay for electrochemical sensing of syphilis DNA was anticipated by using target-guided formation of PANI based on an enzymatically catalyzed method. The synergistic performance of DNA hybridization, strong biotin-streptavidin binding ability, and highly efficient polymerization provide a general platform for efficient, highly sensitive, and selective biosensors for the detection of the specific polA gene fragment of Treponema pallidum. ${ }^{77}$ Using a similar strategy, Deng et $\mathrm{ll}^{78}$ fabricated highly sensitive impedimetric miRNA biosensors using electron-transfer impeding power of PANI with PNA capture probe, target microRNA (miRNA), and G-quadraplex-hemin DNAzyme as the essential biomolecules.

Inspired by the developments in the field of nanomaterials and nanotechnologies, attempts are also being made to investigate PANI nanostructure for the development of nucleic acid biosensors with improved sensing characteristics. In this context, Singh et $\mathrm{al}^{79}$ devised highly sensitive and selective sexually transmitted disease (STD) sensors using electrochemically fabricated PANI nanostructures immobilized with multi-copy gene of Neisseria gonorrhoeae. ${ }^{79}$ This DNA bioelectrode can detect its complementary sequence specifically up to $0.5 \times 10^{-15} \mathrm{M}$ within $60 \mathrm{~s}$ and is also able to distinguish the $N$. gonorrheoea species with Neisseria meningitidis and E. coli cultures. An oligonucleotide sensor was developed using template-free, self-assembled PANI-NT synthesized utilizing the polymeric acid poly(methyl vinyl ether-alt-maleic acid) (PMVEA) and ammonium persulfate as the oxidant. ${ }^{80}$ Well-organized PANI-NT arrays, on the graphite electrode, were used to design ultrasensitive nucleic acid biosensor by Chang et al. ${ }^{81}$ Compared with gold nanoparticles or CNT-based biosensors, the present genosensor provided similar sensitivity without catalytic enhancement, purification, and end group processing. Highly ordered PANI nanowires, on amyloid-like nanofibers, generated from the enzymatic polymerization of self-assembled nonapeptide (aniline-GGAAKLVFF) were used to construct highly sensitive and selective electrochemical biosensors of the hepatitis B virus gene..$^{82}$ Fan et al ${ }^{83}$ utilized the target-guided formation of PANI-NW in nanogaps for the ultrasensitive estimation of miRNA. The developed biosensor was found to quantify miRNA in the range of $10 \mathrm{fM}$ to $20 \mathrm{pM}$ with a detection limit of $5 \mathrm{fM}$.

Enhanced electrochemistry, increased surface area, and promising stability are some of the key features needed for efficient, sensitive, and durable biosensor designs. To achieve these features, tremendous efforts have been made to fabricate the PANI nanocomposites with a number of electroactive entities, ie, AuNPs, CNT, GR, etc, and to investigate their role in deriving the enhanced genosensing characteristics. Feng et a ${ }^{84}$ utilized the synergistic effect of large surface area and enhanced conductivity due to PANI-NT and AuNPs with the film-forming capability of CS to generate electrochemical biosensors for phosphinothricin acetyltransferase (PAT) gene detection. Nascimento et $a l^{85}$ described the fabrication of novel -SH terminated PANI-AuNPs hybrid composite and studied it as an immobilization platform for dengue serotypespecific primers for detecting the dengue genome sequence 
at picomolar concentration. Further, Gangopadhyay et al ${ }^{86}$ reported the designing of an electrochemical genosensor platform with improved sensitivity using PANI-NW decorated with AuNPs. Interestingly, a multianalyte biosensor was designed by Gangopadhyay et a ${ }^{87}$ employing PANI-NW/ AuNPs nanocomposites for the single-platform detection of glucose, DNA, and Lamin A protein. In another report, self-redox signal change of sulfonated PANI enhanced by grapheme oxide (GRO) was adopted to construct direct electrochemical hybridization assay. ${ }^{88}$ The variation in the electrochemical response following hybridization was monitored using electrochemical impedance spectroscopy. For preliminary studies, this nanocomposite was demonstrated to be applicable in the sensing of promyelocytic leukemia/ retinoic acid receptor alpha fusion gene sequence. In a very interesting investigation, authors have revealed strong dependence of DNA sensing behavior of the biosensor on the morphology of the PANI-GRO nanocomposite.$^{89}$ Among the different PANI-GRO morphologies, including small horns, vertical arrays and nanotips, vertical arrays exhibited the maximum sensitivity due to their highest surface area and more accessible space available for DNA binding and thus for hybridization. Similarly, Du et a ${ }^{90}$ have reported an efficient amperometric DNA hybridization sensing platform based on ssDNA/GRO/PANI nanocomposites for quantitative detection of the cauliflower mosaic virus (CaMV35S) gene. Liu et $\mathrm{a}^{91}$ constructed a novel DNA biosensor for the highly sensitive detection of the specific DNA insertion sequence IS6110 of M. tuberculosis, using reduced graphene oxidegold nanoparticles (rGO-AuNPs) as a sensing platform and gold nanoparticles-polyaniline (Au-PANI) as a tracer label for amplification. Owing to the excellent electroactivity of the $\mathrm{Au}-\mathrm{PANI}$ nanocomposite, the resulting DNA biosensor exhibited high sensitivity for the detection of $M$. tuberculosis over a broad linear range with good specificity and stability. Using the synergism between GR and PANI-NW, Bo et $\mathrm{a}^{92}$ have reported sufficiently sensitive, selective, and stable amperometric DNA biosensors. Singh et a ${ }^{93}$ utilized electrochemically fabricated PANI-CNT films as the binding platform for the probe DNA specific to $N$. gonorrhoeae, and used these electrochemically active genosensing electrodes for STD detection. An electrochemical breast cancer biosensor based on a chitosan-co-polyaniline (CS-co-PANI) copolymer coated onto indium tin oxide (ITO) was fabricated by immobilizing the ssDNA probe specific for breast cancersusceptibility gene BRCA1. The genoelectrode exhibited a sensitivity of $2.104 \mu \mathrm{A} \mathrm{fmol}^{-1}$ with a response time of $16 \mathrm{~s}$ and a shelf life of about 6 mo. ${ }^{94} \mathrm{Zhu}$ et $\mathrm{al}^{95}$ have recently reported a highly sensitive impedimetric DNA biosensor based on rodlike bismuth sulfide nano $\left(\mathrm{rBi}_{2} \mathrm{~S}_{3}\right)$ and a PANI nanocomposite film modified ionic liquid-carbon paste electrode (IL-CPE). With the dynamic detection range $\left(1.0 \times 10^{-15}-1.0 \times 10^{-11} \mathrm{M}\right)$, the biosensor displayed good regeneration ability, reproducibility, and stability. Radhakrishnan et $\mathrm{al}^{96}$ revealed highly enhanced electrochemical characteristics of PANI-coated polypyrrole nanotubes that consequently led to enhanced sensitivity and selectivity of their corresponding genoelectrode with a very low detection limit (50 fM). In another investigation, Yang et al ${ }^{19}$ fabricated an electrochemical DNA biosensor for highly sensitive detection of PAT gene sequence based on polyaniline-(mesoporous nanozirconia)/polytyrosine film. Compared with the other electrochemical DNA biosensors based on zirconia-based materials, the proposed biosensor showed its own performance of simplicity, good stability, fine selectivity, and high sensitivity. Furthermore, reports are also available on designing DNA biosensors using PANI-Nafion-6 films as an indicator electrode. ${ }^{98}$ Table 4 is a compilation of different reports available on PANI-based DNA biosensors.

\section{Polyaniline-based immunosensors}

In recent times, PANI-based immunosensors have gained considerable attention due to their rapid detection ability and high sensitivity for their clinical application and environmental monitoring. Immunoassay includes the specific binding affinity of antibodies for an antigen through a lock-and-key model. A promising approach for enhanced immobilization of antibodies in $\mathrm{T} 3$ radioimmunoassay was practiced by Karir et $\mathrm{a}^{99}$ by using a layer of PANI, for preactivating the surface of polystyrene tubes. The surface roughness was measured to be enhanced up to $R_{\mathrm{a}}$ of $20 \mathrm{~nm}$ compared with $6 \mathrm{~nm}$ for unmodified one, thus enhancing antibody adsorption. Beside this, the precision of coating was observed to be improved over a wide range of antigen concentration. As reported by Sai et al, ${ }^{100}$ human IgG could be covalently immobilized on PANI using glutaraldehyde and can be utilized for the development of a piezoelectric immunosensor. The system was capable of detecting the target analyte concentrations in a range of $500 \mathrm{ng} \mathrm{mL}^{-1}-25 \mu \mathrm{g} \mathrm{mL}^{-1}$ with $\sim 10 \%$ nonspecific binding. Yuk et a ${ }^{101}$ demonstrated the use of screen-printed silver electrodes and pulse mode measurement that can enhance the performance of PANI-based polymeric wire biosensors. Muchindu et al ${ }^{102}$ revealed a PANI-polyvinyl sulfonate-based bioelectrode prepared with anti-ochratoxin A (OTA) antibody on Pt disk, which revealed a detection limit of

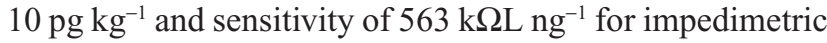




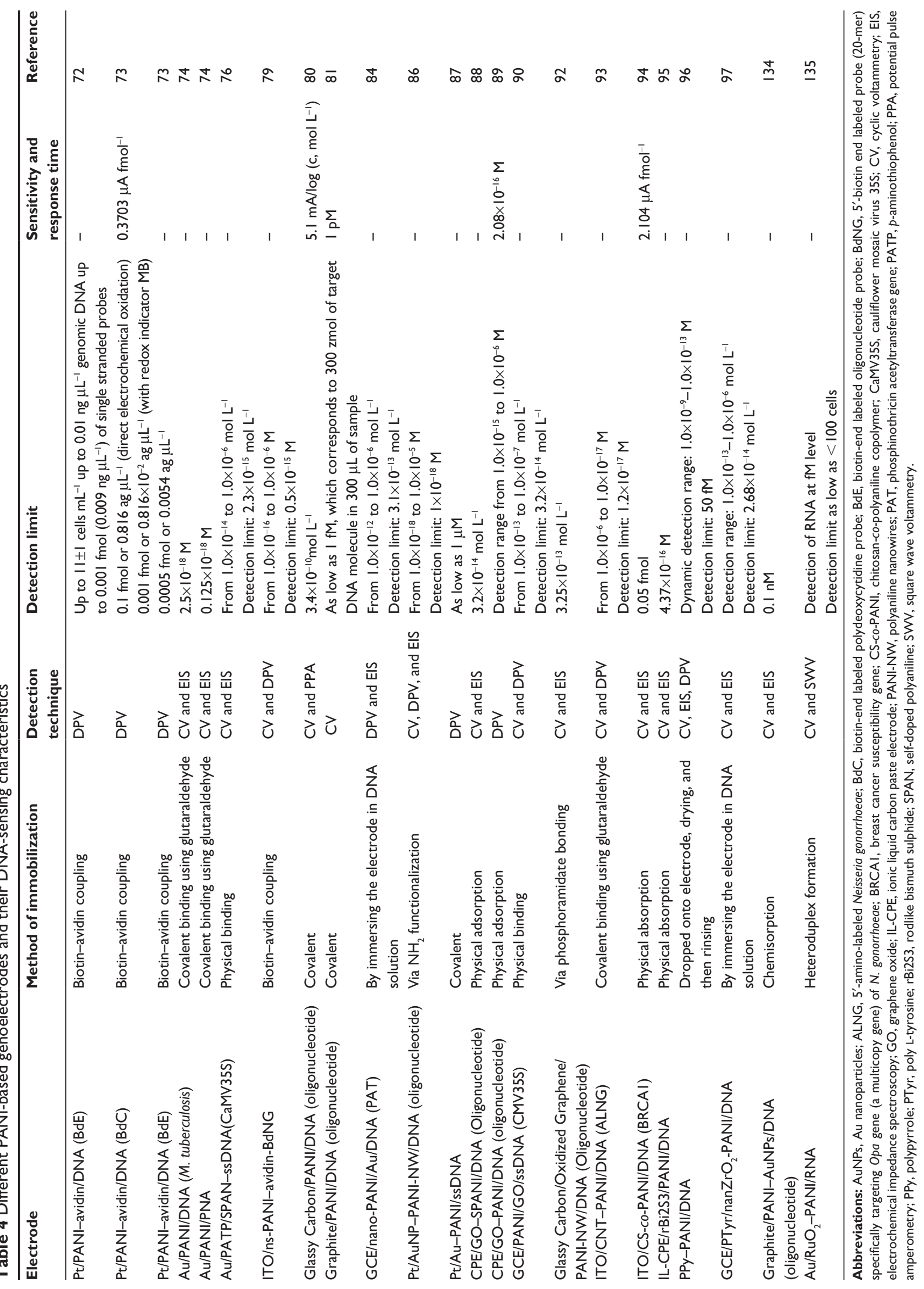


OTA immunosensors. Lee et $\mathrm{al}^{103}$ explored single PANI-NW for the detection of IgG and myoglobin (MY). This system showed great promise for cardiac marker detection and for other proteins. TracyaCui ${ }^{104}$ worked on the same approach of using a single PANI nanowire for the detection of IgE. The detection limit reached a few femtomoles with good aptamer properties like small size, high affinity, and stability. Sun et $\mathrm{a}^{105}$ developed an immunosensor for detecting chlorpyrifos by using AuNPs and PANI/MWCNT-CS nanocomposite. The AuNPs were observed to enhance the electrochemical signal and adsorption capacity of antibodies. Li et $\mathrm{al}^{106}$ explored aptasensors based on thionine, GR-PANI composite film, and AuNPs for the detection of kanamycin. In this approach, AuNPs acted as a transducer between the aptamer and the GR-PANI composites. A detection limit of $8.6 \times 10^{-9} \mathrm{M}$ was obtained with rapid response.

\section{Polyaniline-based phenol, polyphenol, and catecholamine biosensors}

The determination of phenolic compounds is the subject of research in view of their toxic contamination of food, environmental elements, and medical entity. Wang et al ${ }^{107}$ described a novel approach of designing catechol biosensors using polyphenol oxidase (PPO) and PANI with glutaraldehyde as cross-linker. A linear range of $0.2-80 \mu \mathrm{mol} \mathrm{dm}{ }^{-3}$ was obtained with a short response time and good stability. Tan et al ${ }^{108}$ fabricated catechol biosensors based on the immobilization of PPO into PANI. A linear range of 1.25-150 $\mu \mathrm{mol} \mathrm{dm}^{-3}$ was measured with a good reproducibility with $3.1 \%$ relative standard deviation. Also, the stability was secured up to 4 mo with retention of $75 \%$ original activity. Chawla et al ${ }^{109}$ presented a polyphenol biosensor based on laccase immobilized on copper nanoparticles/CS/MWCNT/PANI-modified gold electrode. With a response time of $4 \mathrm{~s}$, the biosensor provided a detection limit of $0.156 \mu \mathrm{M}$ and a wide range of $1-500 \mu \mathrm{M}$. An excellent stability for 300 times use was observed over a period of 7 mo. Rawal et $\mathrm{al}^{110}$ developed a polyphenol biosensor by immobilizing laccase onto AgNPs/ MWCNT/PANI gold electrodes. They employed the sensor for determination of the total phenolic content in tea, alcoholic beverages, and some pharmaceutical formulations. A linear range of $0.1-500 \mu \mathrm{M}$ was obtained with a $6 \mathrm{~s}$ response time and a $0.1 \mu \mathrm{M}$ detection limit. Chawla et al ${ }^{111}$ reported a biosensor for the detection of phenolic content in fruit juices. They performed laccase immobilization on nickel nanoparticles/MWCNT/PANI-modified gold electrode. The sensor responded in $8 \mathrm{~s}$ with a detection limit of $0.05 \mu \mathrm{M}$ and a sensitivity of $0.694 \mu \mathrm{A} \mu \mathrm{M}^{-1} \mathrm{~cm}^{-2}$. Sethuraman et al ${ }^{112}$ fabri- cated a PANI-PPO-based biosensor for polyphenol detection. A linear concentration range of $5 \times 10^{-7}-1.65 \times 10^{-4} \mathrm{~mol} \mathrm{dm}^{-3}$ was obtained with a stability of $25 \mathrm{~d}$ for $65 \%$ original activity. Sadeghi et $\mathrm{al}^{113}$ presented a sensor to detect catechol in tea leaves using $\mathrm{Fe}_{3} \mathrm{O}_{4} / \mathrm{PANI} /$ Laccase/CS biocomposite. A linear range of $0.5-80 \mu \mathrm{M}$ was obtained with a detection limit of $0.4 \mu \mathrm{M}$. Xu and Minteer ${ }^{114}$ revealed a self-doped PANI-based sensor to mediate pyrroloquinoline quinone-dependent enzymatic bioelectrocatalysis. The introduction of sulfonic acid groups into the PANI backbone increased the polymer conductivity in it.

Dopamine detection is considered to be of great interest in medical diagnostics, particularly of pheochromocytoma and stress patients. Yan et $\mathrm{al}^{115}$ worked on $\mathrm{AgCl}-\mathrm{PANI}$ nanocomposites with an excellent electrochemical behavior and a sensitivity of $0.49 \mu \mathrm{A} \mu \mathrm{M}^{-1}$. The presence of PVP prevented the oxidation of ascorbic acid and provided an inhibitive effect. Feng et $\mathrm{al}^{116}$ worked on nitrogen-doped carbon nanotubes (N-CNTs)/PANI composites by immobilizing it on GCE for sensor construction. Feng et al explored PANI-modified GCE-based dopamine sensors, ${ }^{117}$ which showed high catalytic activity in electrochemical oxidation of dopamine. The biosensor was highly selective, with anti-interference ability toward uric acid, ascorbic acid, and glucose with a lower detection limit of $0.5 \times 10^{-9} \mathrm{M}$.

\section{Other biosensors}

PANI has also been investigated for its role as an immobilization platform for the development of amperometric biosensors to detect many other important and clinically significant analytes including, urea, uric acid, creatinine, amino acids, pesticides, etc. Table 5 presents PANI-based biosensors for these analytes.

\section{Scientific concerns and future prospects of polyaniline-based biosensors}

Although PANI is one of the most explored polymers for biosensor development, aging effect, optical and electrochemical instability, and lack of standard/optimized deposition methods limit its potential for commercialization. ${ }^{4}$ Aging of PANI comprises slow and spontaneous degradation of its chemical structure in aerial as well as in vacuum conditions leading to diminished conductivity of the PANI. In vacuum aging, degradation involves the breaking of the imine bonds $(-\mathrm{C}=\mathrm{N})$, leading to the formation of tertiary amines and cross-linking, whereas in aerial aging, oxygen oxidizes the PANI chains by creating carbonyl functionalities that end 


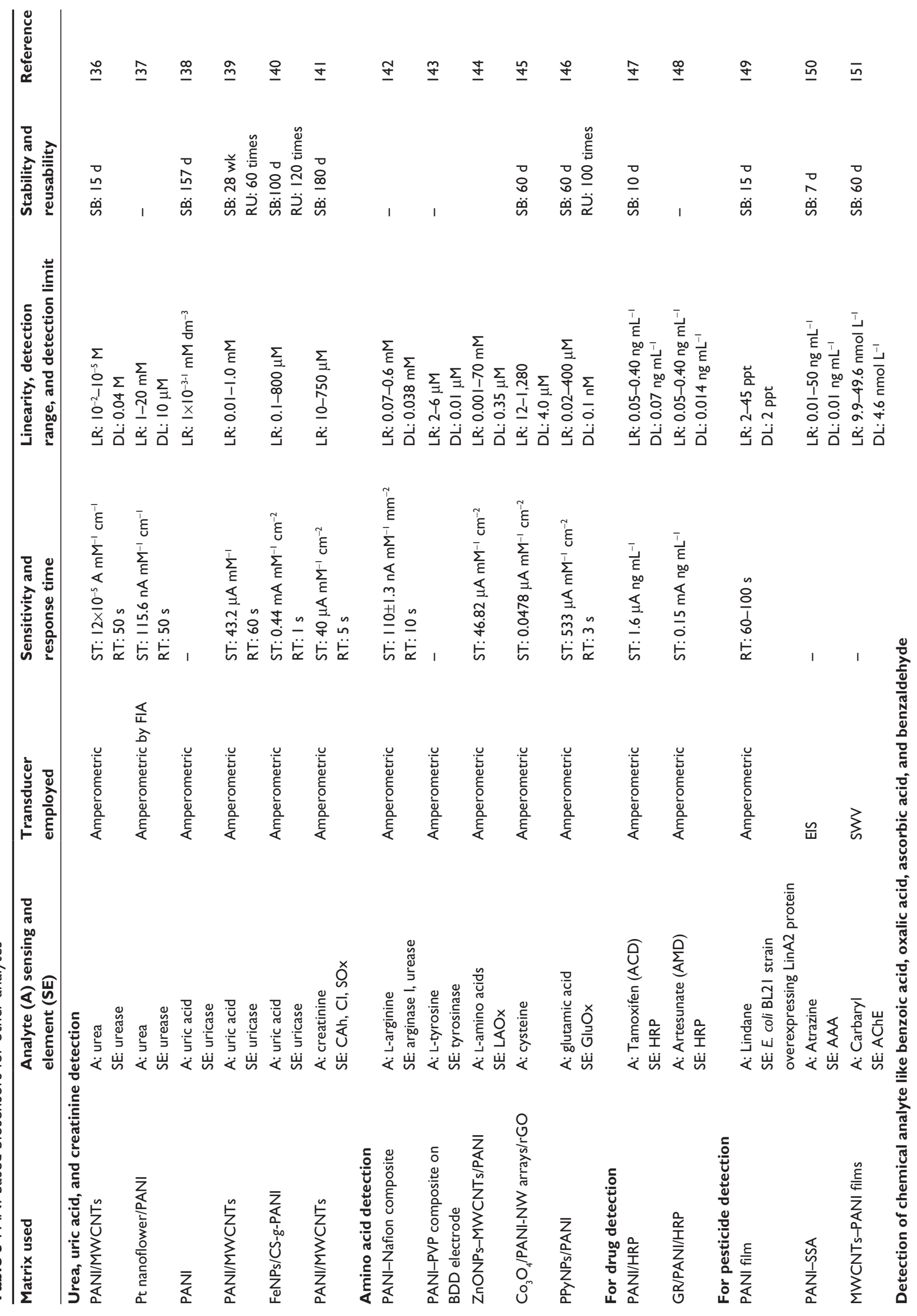




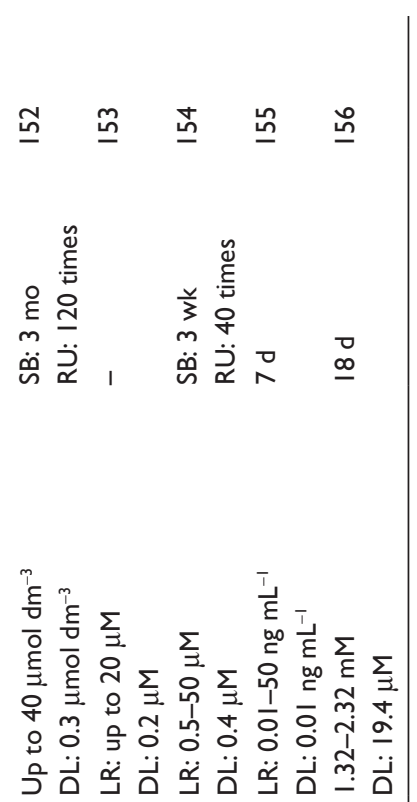

up in chain scissoring. ${ }^{118}$ All these structural defects result in the decreased conjugation length of PANI, which leads to reduced charge carrier mobility and conductivity. The electrochemical instability of PANI can also be easily visualized in the form of an additional peak at $0.5 \mathrm{~V}$ (associated with the damaged phase of PANI) between characteristic PANI peaks at $0.2 \mathrm{~V}$ (related to oxidation of leucoemeraldine to emeraldine) and $0.8 \mathrm{~V}$ (associated with oxidation of emeraldine to pernigraniline) during cyclic voltammetry. This extra peak is due to the oxidation/reduction of soluble electrochemical degradation products, including $p$-benzoquinone. ${ }^{119}$

Chemical, thermal, and electrochemical stability/ cyclability of the PANI was found to be enhanced with the use of metal ion doping, metal/metal oxide nanoparticle incorporation, carbon nanomaterials, and that of anionic surfactants. ${ }^{118-120}$ Thus, advanced engineered nanocomposites with enhanced stability can build a route for commercialization. Conducting polymer hydrogels are a unique class of materials that synchronize the benefits of three-dimensional nanostructures of hydrogels and organic conductors, which make them promising candidates for bioelectronics devices including biosensors. Recently, Zhai et $\mathrm{al}^{34}$ have reported an ultrahigh sensitive glucose biosensor based on PANI-PtNPs hydrogel heterostructures having a minimal response time of $3 \mathrm{~s}$. Target-guided formation of PANI nanowires in nanogapped microelectrode-based biosensor arrays is another efficient design for sensitive genosensor development. ${ }^{83}$ Designing self-doped PANI using ss-DNA-wrapped single-walled carbon nanotubes as the molecular templates provides a smart approach to the design of highly sensitive and stable biosensors. ${ }^{121}$ Finally, aligned PANI-NW, oriented PANI-NT, and PANI nanoarrays are ideal structures for generating highly sensitive, miniaturized biosensing arrays for multianalyte detection. ${ }^{122}$

\section{Conclusion}

In this review, we have comprehensively compiled the literature available on PANI-based biosensors for the last 10 years (2006-2015). Special emphasis has been laid on PANI-based enzymatic biosensors for clinically significant analytes $\left(\mathrm{H}_{2} \mathrm{O}_{2}\right.$, glucose, cholesterol, phenols/polyphenols/catecholamines), genosensors, and immunosensors. Also, a separate subsection was devoted to assembling PANI-based biosensors for the rest of the analytes (urea, uric acid, creatinine, proteins, amino acids, pesticides, etc). This review has not only displayed the biosensing features of all PANI-based biosensors on a single podium but has also unraveled the various imperative 
characteristics of PANI that make it one of the exceptional choices for sensor design. Information has also been provided to demonstrate the implications of PANI, PANI composites, and PANI nanostructures in establishing and promoting the direct electron transfer between the biomolecule and the electrode surface, thus playing a key role in generating thirdgeneration biosensors.

\section{Acknowledgments}

We acknowledge the financial support received from the Singapore Ministry of Health's National Medical Research Council under its Cooperative Basic Research Grant (NMRC/ CBRG/0048/2013) and TCR Grant NMRC/TCR/008-SERI (RWB), R1054/69/2013 (RL).

\section{Disclosure}

The authors report no conflicts of interest in this work.

\section{References}

1. Turner AP. Biosensors: sense and sensibility. Chem Soc Rev. 2013;42: 3184-3196.

2. Kuila T, Bose S, Khanra P, Mishra AK, Kim NH, Lee JH. Recent advances in graphene-based biosensors. Biosens Bioelectron. 2011;26: 4637-4648.

3. Clark LC, Lyons C. Electrode systems for continuous monitoring in cardiovascular surgery. Ann N Y Acad Sci. 1962;102:29-45.

4. Dhand C, Das M, Datta M, Malhotra BD. Recent advances in polyaniline based biosensors. Biosens Bioelectron. 2011;26:2811-2821.

5. Shi L, Xiao Y, Willner I. Electrical contacting of glucose oxidase by DNA-templated polyaniline wires on surfaces. Electrochem Commun. 2004;6:1057-1060.

6. Deepa M, Awadhia A, Bhandari S. Electrochemistry of poly(3,4ethylenedioxythiophene)-polyaniline/Prussian blue electrochromic devices containing an ionic liquid based gel electrolyte film. Phys Chem Chem Phys. 2009;11:5674-5685.

7. Sansinena JM, Gao J, Wang HL. High performance, monolithic polyaniline electrochemical actuators. Adv Funct Mater. 2003;13:703-709.

8. Liu Z, Zhou J, Xue H, Shen L, Zang H, Chen W. Polyaniline/TiO 2 solar cells. Synth Met. 2006;156:721-723.

9. Li M, Guo Yi, Wei Y, Macdiarmid AG, Lelkes PI. Electrospinning polyaniline-contained gelatin nanofibers for tissue engineering applications. Biomaterials. 2006;27:2705-2715.

10. Song E, Choi JW. Conducting polyaniline nanowire and its applications in chemiresistive sensing. Nanomaterials. 2013;3:498-523.

11. Dhand C, Solanki PR, Sood KN, Datta M, Malhotra BD. Polyaniline nanotubes for impedimetric triglyceride detection. Electrochem Commun. 2009;11:1482-1486.

12. Solanki PR, Kaushik A, Ansari AA, Gumana G, Malhotra BD. Horse radish peroxidase immobilized polyaniline for hydrogen peroxide sensor. Polym Adv Technol. 2011;22:903-908.

13. Xua Q, Zhua JJ, Hu XY. Ordered mesoporous polyaniline film as a new matrix for enzyme immobilization and biosensor construction. Anal Chim Acta. 2007;597:151-156.

14. Michira I, Akinyeye R, Somerset V, et al. Synthesis, characterisation of novel polyaniline nanomaterials and application in amperometric biosensors. Macromol Symp. 2007;255:57-69.

15. Bao S, Dua M, Zhang M, et al. Facile fabrication of polyaniline nanotubes/gold hybrid nanostructures as substrate materials for biosensors. Chem Eng J. 2014;258:281-289.
16. Chen X, Chen Z, Zhu J, Xu C, Yan W, Yao C. A novel $\mathrm{H}_{2} \mathrm{O}_{2}$ amperometric biosensor based on gold nanoparticles/self-doped polyaniline nanofibers. Bioelectrochemistry. 2011;82:87-94.

17. Chen S, Fu P, Yin B, Yuan R, Chai Y, Xiang Y. Immobilizing Pt nanoparticles and chitosan hybrid film on polyaniline naofibers membrane for an amperometric hydrogen peroxide biosensor. Bioprocess Biosyst Eng. 2011;34:711-719.

18. Wang X, Yang T, Feng Y, Jiao K, Li G. A novel hydrogen peroxide biosensor based on the synergistic effect of gold-platinum alloy nanoparticles/polyaniline nanotube/chitosan nanocomposite membrane. Electrolysis. 2009;21:819-825.

19. Feng X, Liu Y, Lu C, Hou W, Zhu JJ. One-step synthesis of AgCl/ polyaniline core-shell composites with enhanced electroactivity. Nanotechnology. 2006;17:3578-3583.

20. Song E, Choi JW. A selective hydrogen peroxide sensor based on chemiresistive polyaniline nanowires modified with silver catalytic nanoparticles. J Micromech Microeng. 2014;24:065004.

21. Yadav S, Devi R, Kumari S, Yadav S, Pundir CS. An amperometric oxalate biosensor based on sorghum oxalate oxidase bound carboxylated multiwalled carbon nanotubes-polyaniline composite film. J Biotech. 2011;151:212-217.

22. Luo X, Killard AJ, Morrin A, Smyth MR. Enhancement of a conducting polymer-based biosensor using carbon nanotube-doped polyaniline. Anal Chim Acta. 2006;575:39-44.

23. Komathi S, Gopalan AI, Lee KP. Covalently linked silica-multiwall carbon nanotube-polyaniline network: an electroactive matrix for ultrasensitive biosensor. Biosens Bioelectron. 2009;25:944-947.

24. Granot E, Basnar B, Cheglakov Z, Katz E, Willner I. Enhanced bioelectrocatalysis using single-walled carbon nanotubes (SWCNTs)/polyaniline hybrid systems in thin-film and microrod structures associated with electrodes. Electroanalysis. 2006;18:26-34.

25. Xian Y, Hu Y, Liu F, Xian Y, Wang H, Jin L. Glucose biosensor based on $\mathrm{Au}$ nanoparticles-conductive polyaniline nanocomposite. Biosens Bioelectron. 2006;21:1996-2000.

26. Xu XH, Ren GL, Cheng J, Liu Q, Li DG, Chen Q. Self-assembly of polyaniline-grafted chitosan/glucose oxidase nanolayered films for electrochemical biosensor applications. J Mater Sci. 2006;41:4974-4977.

27. Zhou HH, Chen H, Chen JH, Kuang YF. Polyaniline-graphite composite film glucose oxidase electrode. J Cen South Univ Technol. 2006;13: 653-657.

28. Borole DD, Kapadi UR, Mahulikar PP, Hundiwale DG. Glucose oxidase electrodes of polyaniline, poly (o-anisidine) and their co-polymer as a biosensor: a comparative study. J Mater Sci. 2007;42:4947-4953.

29. Zou Y, Sun LX, Xu F. Biosensor based on polyaniline-Prussian Blue/ multi-walled carbon nanotubes hybrid composites. Biosens Bioelectron. 2007;22:2669-2674.

30. Xu L, Zhu Y, Tang L, Yang X, Li C. Dendrimer-encapsulated Pt nanoparticles/polyaniline nanofibers for glucose detection. J Appl Polym Sci. 2008;109:1802-1807.

31. Liu Y, Feng X, Shen J, Zhu JJ, Hou W. Fabrication of a novel glucose biosensor based on a highly electroactive polystyrene/polyaniline/Au nanocomposite. J Phys Chem B. 2008;112:9237-9242.

32. Liu Z, Wang J, Xie D, Chen G. Polyaniline-coated $\mathrm{Fe}_{3} \mathrm{O}_{4}$ nanoparticlecarbon-nanotube composite and its application in electrochemical biosensing. Small. 2008;4:462-466.

33. Shan D, Wang S, He Y, Xue H. Amperometric glucose biosensor based on in situ electropolymerized polyaniline/poly (acrylonitrile-co-acrylic acid) composite film. Mater Sci Eng C. 2008;28:213-217.

34. Zhai D, Liu B, Shi Y, et al. Highly sensitive glucose sensor based on Pt nanoparticle/polyaniline hydrogel heterostructures. ACS Nano. 2013; 7:3540-3546.

35. Zhao M, Wu X, Cai C. Polyaniline nanofibers: synthesis, characterization, and application to direct electron transfer of glucose oxidase. J Phys Chem C. 2009;113:4987-4996.

36. Wang Z, Liu S, Wu P, Cai C. Detection of glucose based on direct electron transfer reaction of glucose oxidase immobilized on highly ordered polyaniline nanotubes. Anal Chem. 2009;81:1638-1645. 
37. Xu L, Zhu Y, Yang X, Li C. Amperometric biosensor based on carbon nanotubes coated with polyaniline/dendrimer-encapsulated Pt nanoparticles for glucose detection. Mater Sci Eng C. 2009;29:1306-1310.

38. Sheng Q, Zheng J. Bienzyme system for the biocatalyzed deposition of polyaniline templated by multiwalled carbon nanotubes: a biosensor design. Biosens Bioelectron. 2009;24:1621-1628.

39. Wan D, Yuan S, Li GL, Neoh KG, Kang ET. Glucose biosensor from covalent immobilization of chitosan-coupled carbon nanotubes on polyaniline-modified gold electrode. ACS Appl Mater Interfaces. 2010;11: 3083-3091.

40. Kuczynska A, Uygun A, Kaim A, Wilczura-Wachnik H, Yavuz AG, Aldissi M. Effects of surfactants on the characteristics and biosensing properties of polyaniline. Polym Int. 2009;59:1650-1659.

41. Yan W, Feng X, Chen X, Hou W, Zhu JJ. A super highly sensitive glucose biosensor based on Au nanoparticles-AgCl@ polyaniline hybrid material. Biosens Bioelectron. 2008;23:925-931.

42. Ozdemir C, Yeni F, Odaci D, Timur S. Electrochemical glucose biosensing by pyranose oxidase immobilized in gold nanoparticle-polyaniline/ AgCl/gelatin nanocomposite matrix. Food Chem. 2010;119:380-385.

43. Song MJ, Kim JH, Lee SK, et al. Pt-polyaniline nanocomposite on boron-doped diamond electrode for amperometic biosensor with low detection limit. Microchim Acta. 2010;171:249-255

44. Wu J, Yin L. Platinum nanoparticle modified polyaniline-functionalized boron nitride nanotubes for amperometric glucose enzyme biosensor. ACS Appl Mater Interfaces. 2010;3:4354-4362.

45. Tamer U, Seçkin AI, Temur E, Torul H. Fabrication of biosensor based on Polyaniline/Gold nanorod composite. Int J Electrochem. 2011 2011:869742.

46. Nguyen HB, Ngo TTT, Nguyen NT, et al. Graphene patterned polyaniline-based biosensor for glucose detection. Adv Nat Sci Nanosci Nanotechnol. 2012;3:025011.

47. Chen X, Chen Z, Tian R, Yan W, Yao C. Glucose biosensor based on three dimensional ordered macroporous self-doped polyaniline/Prussian blue bicomponent film. Anal Chim Acta. 2012;723:94-100.

48. Qiu JD, Shi L, Liang RP, Wang GC, Xia XH. Controllable deposition of a platinum nanoparticle ensemble on a polyaniline/graphene hybrid as a novel electrode material for electrochemical sensing. Chem A Eur J. 2012;18:7950-7959.

49. Xiang C, Zou Y, Qiu S, Sun L, Xu F, Zhou H. Bienzymatic glucose biosensor based on direct electrochemistry of cytochrome c on gold nanoparticles/ polyaniline nanospheres composite. Talanta. 2013;110:96-100.

50. Zhai D, Liu B, Shi Y, et al. Highly sensitive glucose sensor based on Pt nanoparticle/polyaniline hydrogel heterostructures. ACS Nano. 2013;7:3540-3546.

51. Thakur B, Amarnath CA, Sawant SN. Pectin coated polyaniline nanoparticles for an amperometric glucose biosensor. RSC Adv. 2014;4:40917-40923.

52. Sarauli D, Xu C, Dietzel B, Schulz B, Lisdat F. A multilayered sulfonated polyaniline network with entrapped pyrroloquinoline quinonedependent glucose dehydrogenase: tunable direct bioelectrocatalysis. J Mater Chem B. 2014;2:3196-3203.

53. Antiochia R, Mazzei F, Gorton L, Leech D, Favero G. Composite material based on macroporous polyaniline and osmium redox complex for biosensor development. Electroanalysis. 2014;26:1623-1630.

54. Xu Q, Gu SX, Jin L, et al. Graphene/polyaniline/gold nanoparticles nanocomposite for the direct electron transfer of glucose oxidase and glucose biosensing. Sens Actuators B. 2014;190:562-569.

55. Zhang L, Zhou C, Luo J, et al. A polyaniline microtube platform for direct electron transfer of glucose oxidase and biosensing applications J Mater Chem B. 2015;3:1116-1124.

56. Pahurkar VG, Tamgadge YS, Gambhire AB, Muley GG. Evanescent wave absorption based polyaniline cladding modified fiber optic intrinsic biosensor for glucose sensing application. Measurement. 2015;61: 9-15

57. Tang W, Li L, Zeng X. A glucose biosensor based on the synergistic action of nanometer-sized $\mathrm{TiO}_{2}$ and polyaniline. Talanta. 2015;131: $417-423$
58. Singh S, Solanki PR, Pandey MK, Malhotra BD. Cholesterol biosensor based on cholesterol esterase, cholesterol oxidase and peroxidase immobilized onto conducting polyaniline films. Sens Actuators B. 2006;115:534-541.

59. Singh S, Solanki PR, Pandey MK, Malhotra BD. Covalent immobilization of cholesterol esterase and cholesterol oxidase on polyaniline films for application to cholesterol biosensor. Anal Chim Acta. 2006;568: 126-132.

60. Dhand C, Singh SP, Arya SK, Datta M, Malhotra BD. Cholesterol biosensor based on electrophoretically deposited conducting polymer film derived from nano-structured polyaniline colloidal suspension. Anal Chim Acta. 2007;602:244-251.

61. Dhand C, Solanki PR, Pandey MK, Datta M, Malhotra BD. Electrophoretically deposited polyaniline nanotubes based film for cholesterol detection. Electrophoresis. 2010;31:3754-3762.

62. Dhand C, Das M, Sumana G, et al. Preparation, characterization and application of polyaniline nanospheres to biosensing. Nanoscale. 2010;2:747-754.

63. Matharu Z, Sumana G, Arya SK, Singh SP, Gupta V, Malhotra BD Polyaniline Langmuir-Blodgett film based cholesterol biosensor. Langmuir. 2007;23:13188-13192.

64. Dhand C, Arya SK, Singh SP, Singh BP, Datta M, Malhotra BD. Preparation of polyaniline/multiwalled carbon nanotube composite by novel electrophoretic route. Carbon. 2008;46:1727-1735.

65. Dhand C, Arya SK, Datta M, Malhotra BD. Polyaniline-carbon nanotube composite film for cholesterol biosensor. Anal Biochem. 2008;383: 194-199.

66. Nguyen LH, Nguyen HB, Nguyen NT, Nguyen TD, Tran DL. Portable cholesterol detection with polyaniline-carbon nanotube film based interdigitated electrodes. Adv Nat Sci Nanosci Nanotechnol. 2012;3:015004.

67. Manesh KM, Santhosh P, Gopalan AI, Lee KP. Silica-polyaniline based bienzyme cholesterol biosensor: fabrication and characterization. Electroanalysis. 2010;22:2467-2474.

68. Ruecha N, Rangkupan R, Rodthongkum N, Chailapakul O. Novel paperbased cholesterol biosensor using graphene/polyvinylpyrrolidone/ polyaniline nanocomposite. Biosens Bioelectron. 2014;52:13-19.

69. Zhang H, Liu R, Zheng J. Seed-mediated synthesis of polyaniline/Au nanocomposite and its application for a cholesterol biosensor. Synth Met. 2013;167:5-9.

70. Srivastava M, Srivastava SK, Nirala NR, Prakash R. A chitosanbased polyaniline-Au nanocomposite biosensor for determination of cholesterol. Anal Methods. 2014;6:817-824.

71. Shin YJ, Kameoka J. Amperometric cholesterol biosensor using layerby-layer adsorption technique onto electrospun polyaniline nanofibres. J Indus Eng Chem. 2012;18:193-197.

72. Arora K, Prabhakar N, Chand S, Malhotra BD. Escherichia coli genosensor based on polyaniline. Anal Chem. 2007;79:6152-6158.

73. Arora K, Prabhakar N, Chand S, Malhotra BD. Ultrasensitive DNA hybridization biosensor based on polyaniline. Biosens Bioelectron. 2017;23:613-620.

74. Prabhakar N, Arora K, Singh H, Malhotra BD. Polyaniline based nucleic acid sensor. J Phys Chem B. 2008;112:4808-4816.

75. Prabhakar N, Sumana G, Arora K, Singh H, Malhotra BD. Improved electrochemical nucleic acid biosensor based on polyaniline-polyvinyl sulphonate. Electrochim Acta. 2008;53:4344-4350.

76. Hu Y, Yang T, Li Q, Guan Q, Jiao K. Conjugated self-doped polyanilineDNA hybrid as trigger for highly sensitive reagentless and electrochemical self-signal amplifying DNA hybridization sensing. Analyst. 2013;138:1067-1074.

77. Sheng Q, Wang J, Zheng J, Xu Z, Zhang H. Ultrasensitive electrical biosensing of syphilis DNA using target-guided formation of polyaniline based on enzyme-catalyzed polymerization. Biosens Bioelectron. 2010;25:2071-2077.

78. Deng H, Shen W, Ren Y, Gao Z. A highly sensitive microRNA biosensor based on hybridized microRNA-guided deposition of polyaniline. Biosens Bioelectron. 2014;60:195-200. 
79. Singh R, Prasad R, Sumana G, et al. STD sensor based on nucleic acid functionalized nanostructured polyaniline. Biosens Bioelectron. 2009;24:2232-2238.

80. Zhang L, Peng H, Kilmartin PA, Soeller C, Sejdic JT. Polymeric acid doped polyaniline nanotubes for oligonucleotide sensors. Electroanalysis. 2007;19:870-875.

81. Chang H, Yuan Y, Shi N, Guan Y. Electrochemical DNA biosensor based on conducting polyaniline nanotube array. Anal Chem. 2007;79:5111-5115.

82. Hao Y, Zhou B, Wang F, Li J, Deng L, Liu YN. Construction of highly ordered polyaniline nanowires and their applications in DNA sensing. Biosens Bioelectron. 2014;52:422-426.

83. Fan Y, Chen X, Trigg AD, Tung CH, Kong J, Gao Z. Detection of microRNAs using target-guided formation of conducting polymer nanowires in nanogaps. J Am Chem Soc. 2007;129:5437-5443.

84. Feng Y, Yang T, Zhang W, Jiang C, Jiao K. Enhanced sensitivity for deoxyribonucleic acid electrochemical impedance sensor: gold nanoparticle/polyaniline nanotube membranes. Anal Chim Acta. 2008;616:144-151.

85. Nascimento HP, Oliveira MD, Melo CP, Silva GJ. An impedimetric biosensor for detection of dengue serotype at picomolar concentration based on gold nanoparticles-polyaniline hybrid composites. Colloids Surf B Biointerfaces. 2011;86:414-419.

86. Gangopadhyaya R, Chowdhury AD, De A. Functionalized polyaniline nanowires for biosensing. Sens Actuators B. 2012;171-172: 777-785.

87. Gangopadhyaya R, Chowdhury AD, De A. Highly sensitive electrochemical biosensor for glucose, DNA and protein using goldpolyaniline nanocomposites as a common matrix. Sens Actuators B. 2014;190:348-356.

88. Yang T, Meng L, Wang X, Wang L, Jiao K. Direct electrochemical DNA detection originated from the self-redox signal of sulfonated polyaniline enhanced by graphene oxide in neutral solution. ACS Appl Mater Interfaces. 2013;5:10889-10894.

89. Yang T, Meng L, Zhao J, Wang X, Jiao K. Graphene-based polyaniline arrays for deoxyribonucleic acid electrochemical sensor: effect of nanostructure on sensitivity. ACS Appl Mater Interfaces. 2014;6: 19050-19056.

90. Du M, Yang T, Li X, Jiao K. Fabrication of DNA/graphene/polyaniline nanocomplex for label-free voltammetric detection of DNA hybridization. Talanta. 2012;88:439-444.

91. Liu C, Jiang D, Xiang G, Liu L, Liu F, Pu X. An electrochemical DNA biosensor for the detection of Mycobacterium tuberculosis, based on signal amplification of graphene and a gold nanoparticle-polyaniline nanocomposite. Analyst. 2014;139:5460-5465.

92. Bo Y, Yang H, Hu Y, Yao T, Huang S. A novel electrochemical DNA biosensor based on graphene and polyaniline nanowires. Electrochim Acta. 2011;56:2676-2681.

93. Singh R, Dhand C, Sumana G, et al. Polyaniline/carbon nanotubes platform for sexually transmitted disease detection. J Mol Recognit. 2010;23:472-479.

94. Tiwari A, Gong S. Electrochemical detection of a breast cancer susceptible gene using cDNA immobilized chitosan-co-polyaniline electrode. Talanta. 2009;77:1217-1222.

95. Zhu Q, Gao F, Yang Y, et al. Electrochemical preparation of polyaniline capped $\mathrm{Bi}_{2} \mathrm{~S}_{3}$ nanocomposite and its application in impedimetric DNA biosensor. Sens Actuators B. 2015;207:819-826.

96. Radhakrishnan S, Sumathi C, Dharuman V, Wilson J. Polypyrrole nanotubes-polyaniline composite for DNA detection using methylene blue as intercalator. Anal Methods. 2013;5:1010-1015.

97. Yang J, Wang X, Shi H. An electrochemical DNA biosensor for highly sensitive detection of phosphinothricin acetyltransferase gene sequence based on polyaniline-(mesoporous nanozirconia)/poly-tyrosine film. Sens Actuators B. 2012;162:178-183.

98. Levon K, Nasybulin E, Menshikova I, Sergeyev V, Zezin A. Potentiometric monitoring DNA hybridization with polyaniline/nylon6 working electrode. Polym Sci Ser A. 2009;51:701-707.
99. Karir T, Hassan PA, Kulshreshtha SK, Samuel G, Sivaprasad N, Meera V. Surface modification of polystyrene using polyaniline nanostructures for biomolecule adhesion in radioimmunoassays. Anal Chem. 2006;78:3577-3582.

100. Sai VV, Mahajan S, Contractor AQ, Mukherji S. Immobilization of antibodies on polyaniline films and its application in a piezoelectric immunosensor. Anal Chem. 2006;78:8368-8373.

101. Yuk JS, Jin JH, Alocilja EC, Rose JB. Performance enhancement of polyaniline-based polymeric wire biosensor. Biosens Bioelectron. 2009;24:1348-1352.

102. Muchindu M, Iwuoha E, Pool E, et al. Electrochemical ochratoxin A immunosensor system developed on sulfonated polyaniline. Electroanalysis. 2011;23:122-128.

103. Lee I, Luo X, Cui XT, Yun M. Highly sensitive single polyaniline nanowire biosensor for the detection of immunoglobulin $\mathrm{G}$ and myoglobin. Biosens Bioelectron. 2011;26:3297-3302.

104. TracyáCui X. Ultrasensitive protein detection using an aptamerfunctionalized single polyaniline nanowire. Chem Commun. 2011;47: 6368-6370.

105. Sun X, Qiao L, Wang X. A novel immunosensor based on Au nanoparticles and polyaniline/multiwall carbon nanotubes/chitosan nanocomposite film functionalized interface. Nano-Micro Lett. 2013;5: 191-201.

106. Li F, Guo Y, Sun X, Wang X. Aptasensor based on thionine, graphenepolyaniline composite film, and gold nanoparticles for kanamycin detection. Eur Food Res Technol. 2014;239:227-236.

107. Wang P, Liu M, Kan J. Amperometric phenol biosensor based on polyaniline. Sens Actuators B. 2009;140:577-584.

108. Tan Y, Guo X, Zhang J, Kan J. Amperometric catechol biosensor based on polyaniline-polyphenol oxidase. Biosens Bioelectron. 2010;25:1681-1687.

109. Chawla S, Rawal R, Pundir CS. Fabrication of polyphenol biosensor based on laccase immobilized on copper nanoparticles/chitosan/ multiwalled carbon nanotubes/polyaniline-modified gold electrode. J Biotechnol. 2011;15:39-45.

110. Rawal R, Chawla S, Pundir CS. Polyphenol biosensor based on laccase immobilized onto silver nanoparticles/multiwalled carbon nanotube/polyaniline gold electrode. Anal Biochem. 2011;419: 196-204.

111. Chawla S, Rawal R, Sharma S, Pundir CS. An amperometric biosensor based on laccase immobilized onto nickel nanoparticles/carboxylated multiwalled carbon nanotubes/polyaniline modified gold electrode for determination of phenolic content in fruit juices. Biochem Eng J. 2012;68:76-84.

112. Sethuraman V, Muthuraja P, Manisankar P. Fabrication of an efficient polyaniline-polyphenol oxidase based biosensor for catechol. Anal Methods. 2013;5:6523-6530.

113. Sadeghi S, Fooladi E, Malekaneh M. A new amperometric biosensor based on $\mathrm{Fe}_{3} \mathrm{O}_{4}$ /polyaniline/laccase/chitosan biocomposite-modified carbon paste electrode for determination of catechol in tea leaves. Appl Biochem Biotechnol. 2015:1603-1616.

114. Xu S, Minteer SD. Pyrroloquinoline quinone-dependent enzymatic bioanode: incorporation of the substituted polyaniline conducting polymer as a mediator. ACS Catal. 2014;4:2241-2248.

115. Yan W, Feng X, Chen X, Li X, Zhu JJ. A selective dopamine biosensor based on AgCl@polyaniline core-shell nanocomposites. Bioelectrochemistry. 2008;72:21-27.

116. Feng X, Li R, Ma Y, et al. Nitrogen-doped carbon nanotube/ polyaniline composite: synthesis, characterization, and its application to the detection of dopamine. Sci China Chem. 2011;54: 1615-1621.

117. Feng X, Zhang Y, Yan Z, et al. Self-degradable template synthesis of polyaniline nanotubes and their high performance in the detection of dopamine. J Mater Chem A. 2013;1:9775-9780.

118. Rahmanifar MS, Mousavi MF, Shamsipur S, Riahi S. A study on the influence of anionic surfactants on electrochemical degradation of polyaniline. Polym Degrad Stab. 2006;91:3463-3468. 
119. Sumboja A, Foo CY, Yan J, Yan C, Gupta RK, Lee PS. Significant electrochemical stability of manganese dioxide/polyaniline coaxial nanowires by self-terminated double surfactant polymerization for pseudocapacitor electrode. J Mater Chem. 2012;22:23921-23928.

120. Huang F, Lou F, Chen D. Exploring aligned-carbon-nanotubes@ polyaniline arrays on household al as supercapacitors. Chem Sus Chem. 2012;5:888-895.

121. Ma Y, Ali SR, Dodoo AS, He H. Enhanced sensitivity for biosensors: multiple functions of DNA-wrapped single-walled carbon nanotubes in self-doped polyaniline nanocomposites. $J$ Phys Chem B. 2006;110:16359-16365.

122. Sangodkar H, Sukeerthi S, Srinivas RS, Lal R, Contractor AQ. A biosensor array based on polyaniline. Anal Chem. 1996;68:779-783.

123. Wang P, Li S, Kan J. A hydrogen peroxide biosensor based on polyaniline/FTO. Sens Actuators B. 2009;137:662-668.

124. Singh RP, Kang DY, Oh BK, Choi JW. Polyaniline based catalase biosensor for the detection of hydrogen peroxide and azide. Biotechnol Bioprocess Eng. 2009;14:443-449.

125. Luo X, Killard AJ, Morrin A, Smyth MR. In situ electropolymerised silica-polyaniline core-shell structures: electrode modification and enzyme biosensor enhancement. Electrochim Acta. 2007;52:1865-1870.

126. Luo X, Vidal GD, Killard AJ, Morrin A, Smyth MR. Nanocauliflowers: a screen-printed electrode with a self-assembled polystyrene template and its application in an amperometric enzyme biosensor Electroanalysis. 2007;19:876-883.

127. Kazimierska E, Muchindu M, Morrin A, Iwuoha E, Smyth MR. The fabrication of structurally multiordered polyaniline films and their application in electrochemical sensing and biosensing. Electroanalysis 2009;21:595-603.

128. Silva JV, Pimentel DM, Souto DEP, Luz RCS, Damos FS. Application of horseradish peroxidase/polyaniline/bis (2-aminoethyl) polyethylene glycol-functionalized carbon nanotube composite as a platform for hydrogen peroxide detection with high sensitivity at low potential. J Solid State Electrochem. 2013;17:2795-2804.

129. Feng X, Li R, Ma Y, Fan Q, Huang W. The synthesis of highly electroactive N-doped carbon nanotube/polyaniline/Au nanocomposites and their application to the biosensor. Synth Met. 2011;161:1940-1945.

130. Horng YY, Hsu YK, Ganguly A, Chen CC, Chen LC, Chen KH. Direct-growth of polyaniline nanowires for enzyme-immobilization and glucose detection. Electrochem Commun. 2009;11:850-853.

131. Gopalan AI, Lee KP, Ragupathy D, Lee SH, Lee JW. An electrochemical glucose biosensor exploiting a polyaniline grafted multiwalled carbon nanotube/perfluorosulfonate ionomer-silica nanocomposite. Biomaterials. 2009;30:5999-6005.

132. Solanki PR, Singh S, Prabhakar N, Pandey MK, Malhotra BD Application of conducting poly (aniline-co-pyrrole) film to cholesterol biosensor. J Appl Polym Sci. 2007;105:3211-3219.

133. Khan R, Solanki PR, Kaushik AK, Singh SP, Ahmad S, Malhotra BD Cholesterol biosensor based on electrochemically prepared polyaniline conducting polymer film in presence of a nonionic surfactant. $J$ Polym Res. 2009;16:363-373.

134. Saberi RS, Shahrokhain S, Marrazza G. Amplified electrochemical DNA sensor based on polyaniline film and gold nanoparticles. Electroanalysis. 2013;25:1373-1380.

135. Peng Y, Guangshun Y, Gao Z. A highly sensitive microRNA biosensor based on ruthenium oxide nanoparticle-initiated polymerization of aniline. Chem Commun. 2010;46:9131-9133.

136. Meibodi ASE, Haghjoo S. Amperometric urea biosensor based on covalently immobilized urease on an electrochemically polymerized film of polyaniline containing MWCNTs. Synth Met. 2014;194:1-6.

137. Jia W, Su L, Lei Y. Pt nanoflower/polyaniline composite nanofibers based urea biosensor. Biosens Bioelectron. 2011;30:158-164.

138. Jiang Y, Wang A, Kan J. Selective uricase biosensor based on polyaniline synthesized in ionic liquid. Sens Actuators B. 2007;124:529-534.

139. Arora K, Choudhary M, Malhotra BD. Enhancing performance of uricase using multiwalled carbon nanotube doped polyaniline. Appl Biochem Biotechnol. 2014;174:1174-1187.
140. Devi R, Pundir CS. Construction and application of an amperometric uric acid biosensorbased on covalent immobilization of uricase on iron oxidenanoparticles/chitosan-g-polyaniline composite film electrodepositedon Pt electrode. Sens Actuators B. 2014;193:608-615.

141. Yadav S, Kumar A, Pundir CS. Amperometric creatinine biosensor based on covalently coimmobilized enzymes onto carboxylated multiwalled carbon nanotubes/polyaniline composite film. Anal Biochem. 2011;419:277-283.

142. Stasyuk N, Smutok O, Gayda G, Vus B, Kovalchuk Y, Gonchar M. Bi-enzyme L-arginine-selective amperometric biosensor based on ammonium-sensing polyaniline-modified electrode. Biosens Bioelectron. 2012;37:46-52.

143. Mangombo ZA, Baker P, Iwuoha E, Key D. Tyrosinase biosensor based on a boron-doped diamond electrode modified with a polyaniline-poly(vinyl sulfonate) composite film. Microchim Acta. 2010;170: 267-273.

144. Lata S, Batra B, Singala N, Pundir CS. Construction of amperometric 1-amino acid biosensor based on L-amino acid oxidase immobilized onto ZnONPs/c-MWCNT/PANI/AuE. Sens Actuators B. 2013;188:1080-1088.

145. Wang $\mathrm{L}, \mathrm{Ye} \mathrm{Y}$, Shen $\mathrm{Y}$, et al. Hierarchical nanocomposites of $\mathrm{Co}_{3} \mathrm{O}_{4} /$ polyaniline nanowire arrays/reduced graphene oxide sheets for amino acid detection. Sens Actuators B. 2014;203:864-872.

146. Batra B, Kumari S, Pundir CS. Construction of glutamate biosensor based on covalent immobilization of glutmate oxidase on polypyrrole nanoparticles/polyaniline modified gold electrode. Enzyme Microb Technol. 2014;57:69-77.

147. Radhapyari K, Kotoky P, Khan R. Detection of anticancer drug tamoxifen using biosensor based on polyaniline probe modified with horseradish peroxidase. Mater Sci Eng C. 2013;33:583-587.

148. Radhapyari K, Kotoky P, Das MR, Khan R. Graphene-polyaniline nanocomposite based biosensor for detection of antimalarial drug artesunate in pharmaceutical formulation and biologicalfluids. Talanta. 2013;111:47-53.

149. Prathap A, Chaurasia AK, Sawant SN, Apte SK. Polyaniline-based highly sensitive microbial biosensor for selective detection of lindane. Anal Chem. 2012;84:6672-6678.

150. Deep A, Saraf M, Neha, Bharadwaj MS, Sharma AL. Styrene sulphonic acid doped polyaniline based immunosensor for highly sensitive impedimetric sensing of atrazine. Electrochim Acta. 2014;146: 301-306.

151. Cesarino I, Moraes FC, Machado SA. A biosensor based on polyaniline-carbon nanotube core-shell for electrochemical detection of pesticides. Electroanalysis. 2011;23:2586-2593.

152. Li S, Tan Y, Wang P, Kan J. Inhibition of benzoic acid on the polyaniline-polyphenol oxidase biosensor. Sens Actuators B. 2010;144: $18-22$.

153. Shan D, Shi Q, Zhu D, Xue H. Inhibitive detection of benzoic acid using a novel phenols biosensor based on polyaniline-polyacrylonitrile composite matrix. Talanta. 2007;72:1767-1772.

154. Sadeghi S, Fooladi E, Malekaneh M. A new amperometric benzaldhyde biosensor based on aldehyde oxidase immobilized on $\mathrm{Fe}_{3} \mathrm{O}_{4}-$ grapheneoxide/polyvinylpyrrolidone/polyaniline nanocomposite. Electroanalysis. 2015;27:242-252.

155. Yadav S, Devi R, Kumari S, Yadav S, Pundir CS. An amperometric oxalate biosensor based on sorghum oxalate oxidase bound carboxylated multiwalled carbon nanotubes-polyaniline composite film. J Biotech. 2011;151:212-217.

156. Singh M, Nesakumar N, Sethuraman S, Krishnan UM, Rayappan JBB Electrochemical biosensor with ceria-polyaniline core shell nanointerface for the detection of carbonic acid in blood. J Colloid Interface Sci. 2014;425:52-58. 
Nanobiosensors in Disease Diagnosis

Dovepress

\section{Publish your work in this journal}

Nanobiosensors in Disease Diagnosis is an international, peer-reviewed, open access journal publishing original research, reports, reviews and commentaries including but not confined to: Diagnosis of diseases including cancer, cardiovascular, infectious diseases; Molecular modeling in diagnosis; Enzyme and membrane technologies; and quantum

dot fluorescence technologies for monitoring toxins and pathogens. The manuscript management system is completely online and includes a very quick and fair peer-review system, which is all easy to use. Visit http://www.dovepress.com/testimonials.php to read real quotes from published authors.

Submit your manuscript here: http://www.dovepress.com/nanobiosensors-in-disease-diagnosis-journal 